\title{
Influence of accelerated weathering on the physical and structural properties of poly(lactic-acid)/ poly(3-hydroxybutyrate-co-3-hydroxyvalerate) (PLA/PHBV) blends
}

\author{
A. Antunes ${ }^{*}$, A. S. Luyt, A. Popelka, A. Mahmoud, O. Aljarod, M. K. Hassan, P. Kasak \\ Center for Advanced Materials, Qatar University, PO Box 2713, Doha, Qatar
}

Received 1 December 2020; accepted in revised form 6 February 2021

\begin{abstract}
The paper aims to study the poly(lactic acid) (PLA) and poly(3-hydroxybutyrate-co-3-hydroxyvalerate) (PHBV) blend properties after their degradation under $2000 \mathrm{~h}$ of accelerated weathering conditions following the ASTM D4329 standard. PLA/PHBV blends form a biphasic system shown by the presence of two distinct glass transition temperatures and melting temperatures in differential scanning calorimetry (DSC) analysis, attributed to the neat polymers regardless of the blend composition. Scanning electron microscopy (SEM) indicated that the addition of high PHBV content to the blend results in a very heterogeneous surface with cavities available for moisture and UV penetration resulting in easier bulk and in-depth degradation of the samples. Thus, the wettability properties (evaluated by contact angle measurements) of the blends changed significantly over the weathering time. On the other hand, the PLA content delays the degradation process of the blends because of the resultant crystallinity from weathering degradation which exhibits a physical barrier to protect the PHBV fraction. PHBV improves the toughness of the blend and acts as a nucleating agent for PLA, promoting its crystallinity during sample preparation. Fourier-transform infrared (FTIR) confirmed photodegradation of all the blends via a Norrish II mechanism.
\end{abstract}

Keywords: polymer blends and alloys, poly(lactic-acid), poly(3-hydroxybutyrate-co-3-hydroxyvalerate), accelerated weathering degradation

\section{Introduction}

Synthetic materials such as plastics have numerous applications in packaging, automobile manufacturing, food production, pharmaceuticals, and other areas. Polymers present characteristics not achieved in other materials, such as low cost, low weight and high durability. Consequently, the high volume of production and their short lifespan have resulted in an increase in plastic waste and environmental pollution. Only the plastic waste generated annually in coastal countries reached 275 million metric tons, entering the ocean and accumulating in landfills. To stop the mountain of discarded plastic from growing, scientists are encouraged to find materials derived from renewable resources, which show comparable or enhanced properties to those of petroleum-based plastics. One solution to be considered is the development and use of biodegradable polymers, for example poly(lactic acid) (PLA), polyhydroxyalkanoates (PHAs), poly ( $\varepsilon$-caprolactone) (PCL), poly (p-dioxanone) (PPDO) and poly(butylene succinate) (PBS) $[1,2]$.

PLA is one of the most promising biodegradable bioplastics due to its physical and chemical properties and full biodegradability. It exhibits an amorphous or semi-crystalline morphology depending on the $\mathrm{L}$ and 
D isomers content, but the thermal and mechanical history from fabrication processes have also a remarkable impact on the material properties. PLA can be produced from renewable sources, for example corn starch and sugar beet, by direct condensation polymerization of lactic acid or by ring-opening polymerization of lactide. However, the application of neat PLA is strongly limited by its brittleness. Another good candidate for non-fossil polymers is poly(3-hydroxybutyrate-co-3-hydroxyvalerate) (PHBV), which is a thermoplastic aliphatic polyester, produced naturally by bacterial fermentation with excellent biocompatible and biodegradable properties. PHBV exhibits low glass transition temperatures and high toughness, but it is relatively expensive. Meanwhile, PLA prices have dropped from 1000 US\$ per kg to a few US\$ per $\mathrm{kg}$ during the last 20 years and are now at a price level similar to that of polystyrene $[1,2]$. Several papers focused on the production of PLA/ PHBV blends. Polymer blending is an effective approach to create a material with some desired properties by combining the different advantages of two or more polymers. The resulting properties are typically a compromise between those of the parent polymers. PHBV/PLA blends form a biphasic system. This immiscibility was shown by several authors, and the compatibilization has also been studied, because enhanced properties have been found blending these two biopolymers. The production of blends based on PHBV and PLA can be an efficient and promising route to extend the applications as biodegradable materials, considering the possibility to finely tune their functional properties by adjusting the respective proportions of each component [3-6].

It is important to focus on the weathering degradation of waste plastic left in oceans and landfills, as well as the application of these blends in real life products, because one should know their behavior after a certain lifespan. Some studies were done on neat PLA or neat PHBV to investigate the photo [7, 8], hydrolytic [9], as well as soil and enzymatic degradation $[10,11]$. In our previous studies $[12,13]$ we prepared and investigated the accelerated weathering degradation of neat PLA and neat PHBV, as well as the degradation behavior of PLA and PHBV composites containing rutile- $\mathrm{TiO}_{2}$ nanoparticles. Accelerated weathering tests were conducted in weathering chambers that mimic natural environmental conditions. The blend samples were exposed to UV radiation and controlled humidity and temperature. The morphology, chemical structure, molecular weight, crystallization, as well as mechanical and thermal properties were thoroughly studied. Accelerated weathering exposure had a significant effect on the general properties of the neat PLA and neat PHBV samples as a result of degradation. Neat PLA changed its amorphous character and developed semi-crystallinity because of the reorganization of small size chains that formed as a result of chain cleavage during the moisture and UV exposure, while neat PHBV was completely degraded after the same study conditions However, to the best of our knowledge, there are no studies regarding this behavior on PLA/PHBV blends.

In this study, 75/25, 50/50 and 25/75 w/w PLA/PHBV were investigated. The degradation behavior of each blend under controlled conditions of accelerated weathering was studied to better understand the longterm degradation of PLA/PHBV blends after alternating cycles of UV light and moisture at a controlled temperature of $50^{\circ} \mathrm{C}$ for cycles of 500 up to $2000 \mathrm{~h}$.

\section{Experimental}

\subsection{Materials}

The PLA used in this study is a high molar mass biopolymer (Ingeo ${ }^{\mathrm{TM}}$ Biopolymer 2003D), obtained from NatureWorks, LLC (USA). It is transparent with a density of $1.24 \mathrm{~g} \cdot \mathrm{cm}^{-3}$, melt flow index of $6.0 \mathrm{~g} / 10 \mathrm{~min}\left(2.16 \mathrm{~kg}\right.$ and $\left.210^{\circ} \mathrm{C}\right)$, glass transition temperature of $\sim 55^{\circ} \mathrm{C}$ and a melting temperature of $\sim 150^{\circ} \mathrm{C}$. The molar mass dispersity of the neat PLA is 1.3 , showing 71500 and $89500 \mathrm{~g} \cdot \mathrm{mol}^{-1}$, respectively, for number average $\left(M_{\mathrm{n}}\right)$ and weight average $\left(M_{\mathrm{w}}\right)$ molecular weights.

The PHBV containing 25\% of 3-hydroxyvalerate segments in the polymer was obtained from Pensieve Technology Co., Ltd. (Wuhan, China). It is light yellow with a density of $1.24 \mathrm{~g} \cdot \mathrm{cm}^{-3}$, a melt flow index of $3.2 \mathrm{~g} / 10 \mathrm{~min}$, glass transition temperature around $-45^{\circ} \mathrm{C}$ and a melting temperature of $\sim 90^{\circ} \mathrm{C}$. The molar mass dispersity of the neat PHBV is 1.41 , showing 59228 and $83362 \mathrm{~g} \cdot \mathrm{mol}^{-1}$, respectively, for $M_{\mathrm{n}}$ and $M_{\mathrm{w}}$.

Ethylene glycol (>98\% FLUKA, Morris Plains, New Jersey, USA), formamide ( $>98 \%$ FLUKA) and ultrapure water (prepared by Purification System Direct Q3, Millipore Corporation, Molsheim, France) were used as testing liquids for wettability analyses. 


\subsection{Preparation method}

The samples were prepared via melt-mixing using a Plastograph EC (Brabender GmbH, Duisburg, Germany). PLA and PHBV were dried in an oven at $50^{\circ} \mathrm{C}$ overnight prior to mixing. $25 / 75,50 / 50$ and $75 / 25 \mathrm{w} / \mathrm{w}$ PLA/PHBV blends were mixed at $170^{\circ} \mathrm{C}$ and $30 \mathrm{rpm}$ screw speed for $10 \mathrm{~min}$. The samples were then placed between two pieces of stainlesssteel plate covered by a release foil, and molded into $1 \mathrm{~mm}$ thick sheets at the same temperature for $5 \mathrm{~min}$ using a hydraulic press (Carver, Inc., Wabash, Indiana, USA) at a pressure of 50 bar. The sheets were allowed to cool at room temperature and then cut into dumbbell and rectangular shapes as further described. Neat PLA and neat PHBV were prepared according to our previous works $[12,13]$.

\subsection{Accelerated weathering test}

The accelerated weathering of the PLA/PHBV samples was conducted in an accelerated weathering tester Model QUV/se (Q-LAB, Westlake, Ohio, USA). The weathering conditions were according to Cycle-C of the ASTM D4329 standard. Fluorescent UV lamps (UVA-340) with $0.76 \mathrm{~W} \cdot \mathrm{m}^{-2}$ irradiance (wavelength $340 \mathrm{~nm}$ ) were used with cycles of $8 \mathrm{~h}$ UV irradiation at $50^{\circ} \mathrm{C}$, followed by 4 h dark at $50^{\circ} \mathrm{C}$ under $100 \%$ condensing humidity. These consecutive cycles were applied to the specimens attached to the test panels without any interruption. The effects of the accelerated weathering were investigated for four exposure periods: 0, 500, 1000, and $2000 \mathrm{~h}$. Samples were collected for analysis after each period, and they are designated as ' $x \mathrm{PLA} / y \mathrm{PHBV} / z \mathrm{~h}$ ', where $x$ and $y$ show the PLA and PHBV content in each blend and $z$ denotes the accelerated weathering period in hours.

\subsection{Characterization techniques}

\subsubsection{Surface visual changes}

After each accelerated weathering period, visual inspection of variations in color, gloss, transparency and roughness of the specimens was carried out. The visual inspection was made by comparing photographic images of the non-weathered and weathered specimens.

\subsubsection{Scanning electron microscopy (SEM)}

Scanning electron microscopy (SEM) analyses of the samples were performed to obtain 2D images of the surfaces and fracture surfaces using a NanoSEM
450 electron microscope (FEI Nova, Hillsboro, Oregon, USA), at an accelerating voltage of $2-5 \mathrm{kV}$. A thin Au layer of a few nanometers thick was sputtercoated onto the surfaces and cross-sections of the samples to obtain high-resolution images and to avoid the accumulation of electrons on the measured layer [14].

\subsubsection{Atomic-force microscopy (AFM)}

Detailed information about three-dimensional changes in the surface topography of the PLA/PHBV surface was obtained using atomic force microscopy (AFM). An MFP-3D system (Oxford Instruments Asylum Research, Santa Barbara, California, USA) equipped with an AC160TS cantilever (Al reflex-coated Veeco model, OLTESPA, Olympus, Tokyo, Japan) was used for the image scanning and determination of the mechanical properties by the application of an amplitude modulation-frequency modulation (AM-FM) mode. This mode represents an extension of the standard tapping mode, while the AFM cantilever with tip is excited simultaneously at both its fundamental resonant frequency and another eigenmode. The fundamental resonance allowed the observation of the topographical structures of the sample and tracking of the frequency, and the amplitude shift of the other eigenmode was used for an investigation of the mechanical properties. Young's modulus of the samples was obtained using a general Hertz model describing the contact mechanics between the AFM tip and the sample. A PLA standard with known Young's modulus (3.04 GPa) was first used for the cantilever calibration to evaluate its elasticity. This cantilever elasticity $\left(412.10 \mathrm{kPa} \cdot \mathrm{Hz}^{-1}\right)$ was then used to obtain the mean values of the Young's modulus of the PLA/ PHBV blends in the entire surface area.

\subsubsection{X-ray diffraction analysis (XRD)}

$\mathrm{X}$-ray diffraction (XRD) analyses were performed using an Empyrean (Panalytical, Almelo, The Netherland) equipped with a $\mathrm{Cu} \mathrm{K} \alpha(\lambda=0.1540 \mathrm{~nm})$ source. The generator was operated at $40 \mathrm{~mA}$ and $45 \mathrm{kV}$. Samples were scanned from 5 to $60^{\circ}$ at a scanning rate of $0.0130^{\circ} 2 \theta$.

\subsubsection{Surface energy}

The changes in surface wettability of the PLA/PHBV blends were evaluated by static contact angle $(C A)$ measurements using the sessile drop method. A surface energy analysis system OCA35 (DataPhysics, 
Filderstadt, Germany) equipped with a CCD camera was used for this purpose. Water, formamide and ethylene glycol were used as testing liquids to evaluate the total surface free energy, as well as the polar and dispersive components, using the conventional Owens-Wendt-Rabel-Kaelble method. A droplet of approximately $3 \mu \mathrm{l}$ from each testing liquid was placed on the air-facing samples. The contact angle was calculated after around $3 \mathrm{~s}$ to allow reaching of thermodynamic equilibrium between the liquid and the sample surface. The reported value for each testing liquid corresponds to the mean of at least five measurements taken on different parts of the substrate surface.

\subsubsection{Fourier-transform infrared (FTIR) spectroscopy}

Fourier-transform infrared (FTIR) spectroscopy with attenuated total reflectance accessory was used to identify the chemical composition of the samples after weathering tests. An FTIR Frontier spectrometer (PerkinElmer, Massachusetts, USA) equipped with a ZnSe crystal was used for these analyses, capturing data from $1.66 \mu \mathrm{m}$ penetration depth, using an average of 8 scans with a resolution of $4 \mathrm{~cm}^{-1}$. The FTIR spectra were obtained from the middle infrared region (4000-500 $\mathrm{cm}^{-1}$ wavenumber).

\subsubsection{Differential scanning calorimetry (DSC)}

The DSC analyses were performed in a DSC 8500 (PerkinElmer, Massachusetts, USA) differential scanning calorimeter. The PLA/PHBV samples (5-10 mg) were heated from 30 to $180^{\circ} \mathrm{C}$, respectively, at $10^{\circ} \mathrm{C} \cdot \mathrm{min}^{-1}$. The melting enthalpies of the PLA/ PHBV blends were determined from the DSC curves, and Equation (1) was used to calculate the degrees of crystallinity of PLA and PHBV in the blends, where $\Delta H_{\mathrm{m}}$ is the measured melting enthalpy, $\Delta H_{\mathrm{cc}}$ is the measured cold crystallization enthalpy (which has a negative value because crystallization is exothermic - therefore the use of $\left|\Delta H_{\mathrm{m}}\right|$ and $\left|\Delta H_{\mathrm{cc}}\right|$ in Equation (1)), $\Delta H_{\mathrm{m}}^{\circ}$ is the enthalpy of melting of the $100 \%$ crystalline polymer, with a value of $93.6 \mathrm{~J} \cdot \mathrm{g}^{-1}$ for PLA [15] and $109.5 \mathrm{~J} \cdot \mathrm{g}^{-1}$ for PHBV [16], and $W$ is the polymer mass fraction in the analyzed sample. A second heating scan (curves are not shown here) was used to analyze the glass transition temperature of PHBV, $T_{\mathrm{g}}$ PHBV:
$X_{\mathrm{C}}[\%]=\frac{\left|\Delta H_{\mathrm{m}}\right|-\left|\Delta H_{\mathrm{cc}}\right|}{W \cdot \Delta H_{\mathrm{cc}}} \cdot 100$

\subsubsection{Thermogravimetric analysis (TGA)}

A TGA4000 (PerkinElmer, Waltham, Massachusetts, USA) thermogravimetric analyser (TGA) was used to analyze the thermal degradation behavior of the samples. The analyses were done from 30 to $600^{\circ} \mathrm{C}$ at a heating rate of $10^{\circ} \mathrm{C} \cdot \mathrm{min}^{-1}$ under nitrogen flow $\left(20 \mathrm{ml} \cdot \mathrm{min}^{-1}\right)$. The sample masses were $10-15 \mathrm{mg}$.

\subsubsection{Tensile testing}

The tensile properties were determined at room temperature in a Lloyd LR $50 \mathrm{k}$ Plus (Lloyd Instruments Ltd., Fareham, United Kingdom) universal testing machine at a stretching speed of $10 \mathrm{~mm} \cdot \mathrm{min}^{-1}$ (ASTM D638). The gauge length was $25 \mathrm{~mm}$, and the sample (dumbbell shape) width and thickness were, respectively, 3.25 and $1 \mathrm{~mm}$.

\section{Results and discussion}

\subsection{Surface morphology}

The surfaces of the PLA/PHBV blends were visually evaluated after 500, 1000 and $2000 \mathrm{~h}$ of accelerated weathering, and compared to the non-weathered samples. Changes in the color and transparency were not perceptible once the incorporation of PHBV into PLA caused a transformation from an optical transparent to an opaque system. Neat PLA was completely transparent due to its amorphous structure before weathering [12].

Before weathering exposure, the PLA/PHBV blends presented a glossy and smooth surface. Despite the fact that the visual aspect was similar, the SEM (Figure 1 and Figure 2) and AM-FM (Table 1) showed different characteristics.

After $500 \mathrm{~h}$ of weathering no significant changes were visually observed for all the samples. However, it was observed that the incorporation of $25 \mathrm{wt} \%$ of PLA in the PHBV matrix was not enough to protect PHBV from weathering degradation after $1000 \mathrm{~h}$ of accelerated weathering. Thus, the 25PLA/75PHBV/ $1000 \mathrm{~h}$ blend shows some cracks formed on the surface. Cracks and voids allow UV and moisture penetration from the surface to the bulk and will accelerate the degradation process. After $2000 \mathrm{~h}$ this blend was visually degraded, and cracks from contraction 
and expansion behavior in the polymer during the drying (UV light) and wetting (condensation) cycles promoted physical degradation, as well as chemical changes that will be discussed later.

Initially, all the blends were white and opaque. However, an increase in the yellowness level of the specimens was visually observed with increasing weathering time, changing the white color of the samples to a pale yellow. The color change of the samples can be explained by the formation of chromophore groups (e.g., carboxyl, carbonyl, ketone, aldehyde, hydroxyl, ester, etc.) and conjugated double bonds in
75PLA/25PHBV

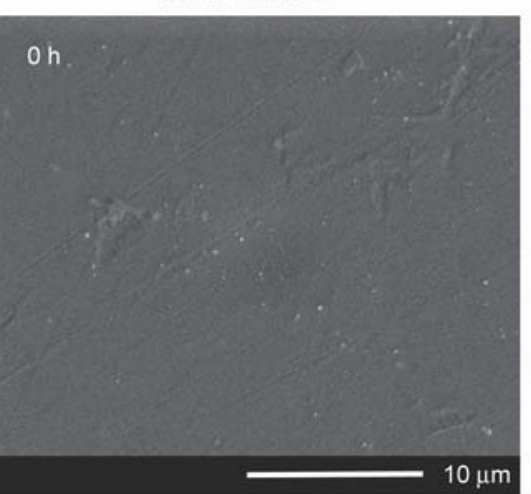

$500 \mathrm{~h}$

$10 \mu \mathrm{m}$
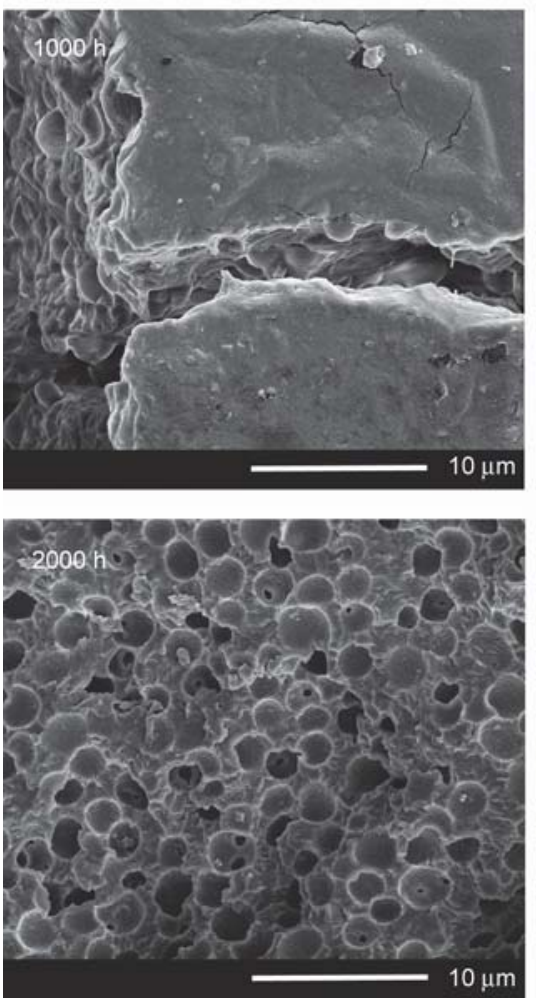

50PLA/50PHBV
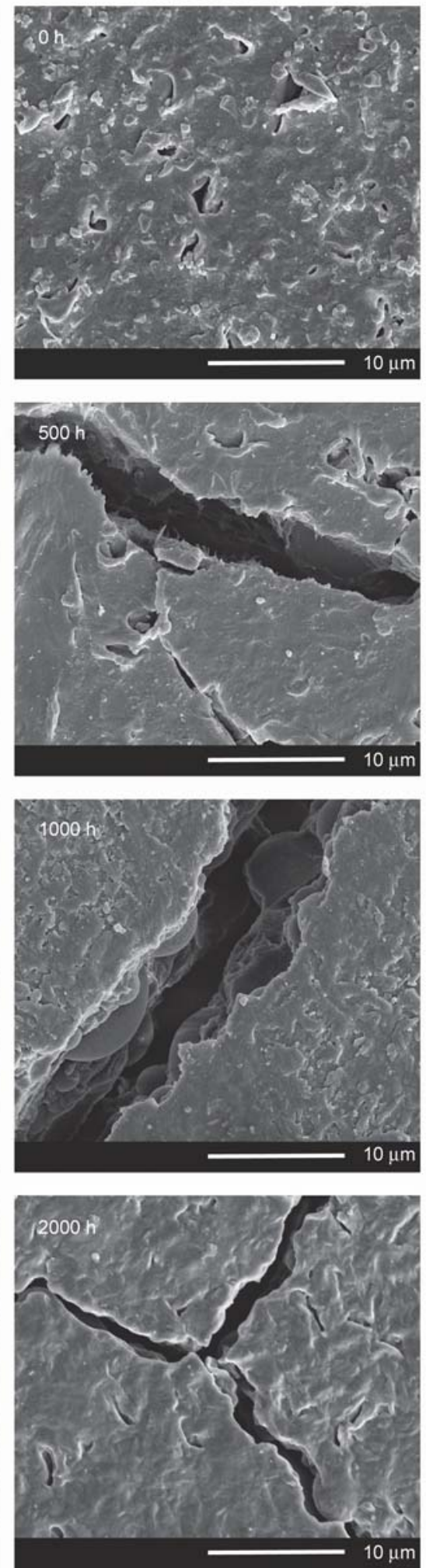

25PLA/75PHBV


Figure 1. SEM images of the surface of the PLA/PHBV blends before and after accelerated weathering. 
the polymers through the photo-oxidative reactions during the accelerated weathering exposure [13]. This was detected in all the studied blends after $2000 \mathrm{~h}$. A loss in the smooth character of the 50PLA/50PHBV surface was also visually detected after accelerated weathering, but cracks were not identified as noticed for the 25PLA/75PHBV blend. Decreasing the amount of PHBV exhibited the same visual characteristics over the weathering time, which suggests that significant amounts of PHBV underwent severe degradation during weathering exposure, while high PLA ratios delayed this degradation.

SEM was used to investigate the effects of the accelerated weathering exposure on the morphology of the surface (Figure 1) and of the cross-section (Figure 2) of the PLA/PHBV blends. 75PLA/25PHBV/0h shows a smooth and uniform surface, like that of neat PLA, despite the presence of a small amount of PHBV. On the other hand, the surfaces of the specimens containing a high PHBV content, 25PLA/ $75 \mathrm{PHBV} / 0 \mathrm{~h}$, were less uniform showing some imperfections due to the PHBV crystalline structure [17]. The immiscibility of the two materials is clearly visible in the 50PLA/50PHBV blend. This blend presented the roughest surface, and some holes and cavities were noticed.
From the images of the fractured surfaces before weathering, one observes small dispersed spheres in the 25PLA/75PHBV/0h blend. With the increase of the PLA ratio in the blends, the spheres became larger in the 50PLA $/ 50 \mathrm{PHBV} / 0 \mathrm{~h}$ sample, but less perceptible in the 75PLA $/ 25 \mathrm{PHBV} / 0 \mathrm{~h}$ sample due to its conversion to the continuous phase of the blend. Thus, the spherical particles observed in the SEM images of the $75 \mathrm{PLA} / 25 \mathrm{PHBV} / 0 \mathrm{~h}$ refer to the PHBV fraction. Two obvious phases were found in all the images of the fractured surfaces, which clearly indicates that the PLA/PHBV blends were not miscible. After $500 \mathrm{~h}$ of weathering, 75PLA/25PHBV/500h still shows a homogenous surface but after $1000 \mathrm{~h}$ some cracks developed, and the bulk of the sample can be seen. Spherical particles can be found, as already observed in the cross-sectional images before weathering, indicating a phase-separated morphology. Increasing the weathering time up to $2000 \mathrm{~h}$, the surface of the 75PLA/25PHBV/2000h sample was converted into an infinite number of spherical cavities around $2.5 \mu \mathrm{m}$, leaving the bulk of the specimen completely exposed to degradation. Knowing the typical morphology of immiscible polymer blends, this result confirms PHBV to be dispersed in the continuous phase of PLA. An interesting result was found
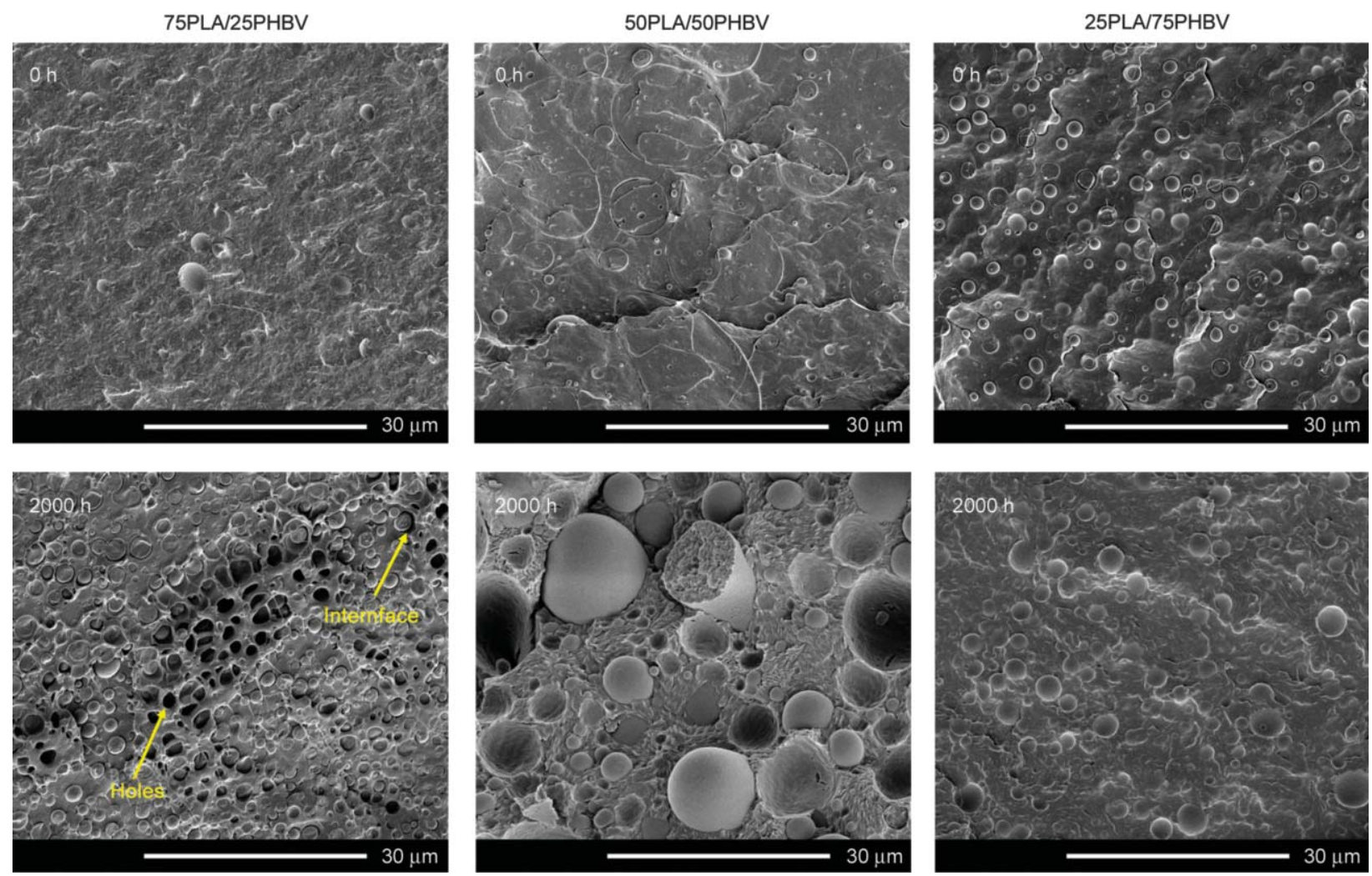

Figure 2. SEM images of the cross-section of the PLA/PHBV blends before and after accelerated weathering. 
in the SEM cross-sectional image of the 75PLA/ 25PHBV/2000h. A cavity was observed around each PHBV particle, which confirms the weak interaction between the two polymers as observed by Gasmi et al. [18]. In addition, some spherical holes were also noted as suggested by the surface image from the same sample. These results strongly suggest the earlier degradation of PHBV compared to PLA, which occurs firstly in the interface regions between the two components. During the degradation process, water and UV contact with PLA and PHBV fractions gave rise to the erosion of the PLA fraction but the collapse of the PHBV fraction. A scheme of the suggested physical degradation process is shown in Figure 3. Thus, the smooth surface disappeared, replaced by a porous morphology, which was not visually detected due to the size of these cavities but well noticed in the SEM images.

With the increase in the PHBV content the degradation process of the blends seems to have occurred earlier. The already present small cavities in the nonweathered 50PLA/50PHBV sample promoted its own degradation. Water absorption and diffusion through the polymer bulk was higher, resulting in faster hydrolytic degradation of the polymer, leading to long chain scission in the small oligomers. In addition, the more cracks there were, the more area was available into the bulk for UV penetration and degradation. Thus, 50PLA/50PHBV/500h showed large and deeper cracks on its surface that resulted from degradation, and after $1000 \mathrm{~h}$ the spherical morphology of the bulk of the sample, as already observed in the 75PLA/25PHBV blends, was obvious. Regarding the cross-sectional images of 50PLA/50PHBV before and after weathering, it is not clear which phase corresponds to which polymer. A co-continuous morphology was expected, but large spheres containing small spheres inside were observed. Gasmi et al. [18] suggested this to be small spheres of PHBV inside the bigger amorphous PLA spheres.

In the same way, the 25PLA/75PHBV blend showed that the degradation process already started after $500 \mathrm{~h}$. Some holes were observed, and a heterogeneous appearance of the surface was also noted (Figure 1). The small and short-chain oligomers from this degradation formed on available re-organized and crystalline structures (as further discussed in the DSC section). Thus, the crystalline structures were close and promoted a rougher surface [17], as was also noticed in 25PLA/75PHBV/2000h. The images of the fractured surfaces (Figure 2) showed the same spherical morphology, which remained after weathering. While 75PLA/25PHBV/2000h showed holes from the complete degradation of the PHBV fraction, 25PLA/75PHBV showed better-defined spheres. Studying this morphology, we can conclude that the PHBV was first degraded as shown in Figure 3, leaving the PLA in the blend exposed and resulting in a completely cracked surface as visually observed.

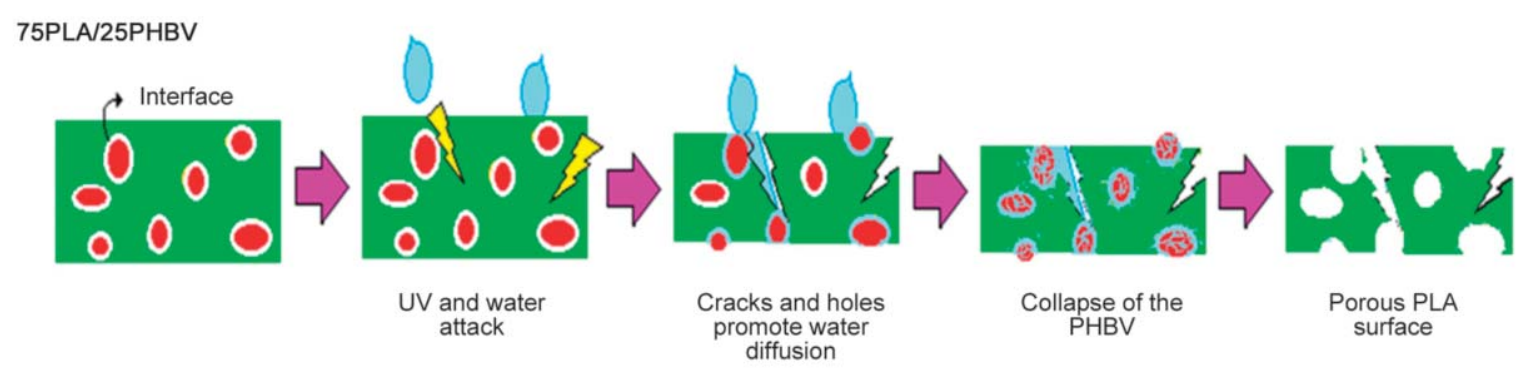

25PLA/75PHBV

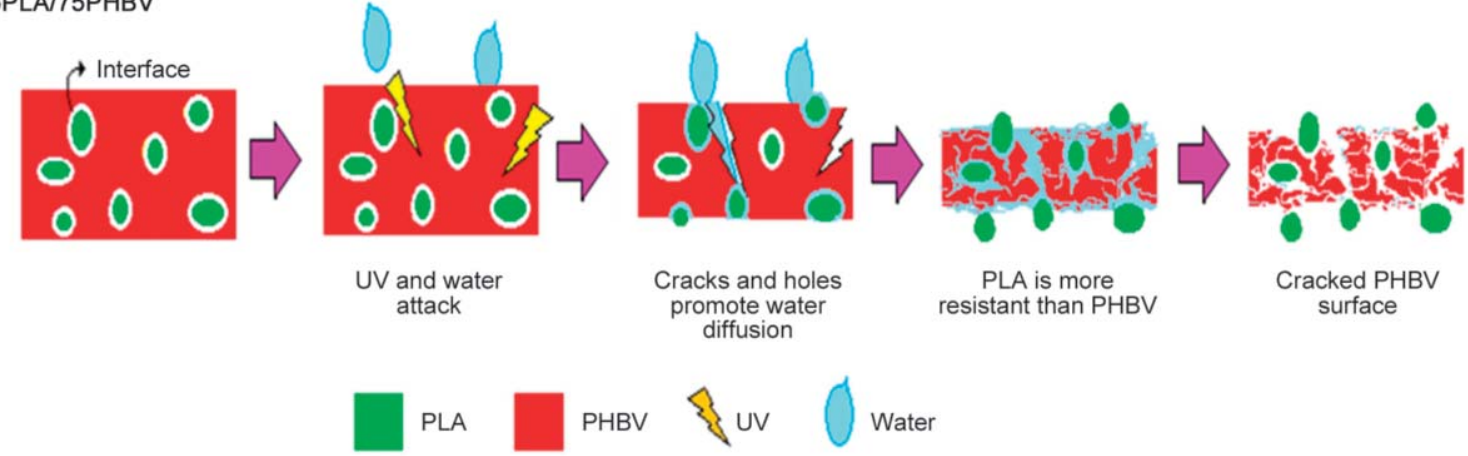

Figure 3. Schematic representations of the accelerated weathering degradation of the PLA/PHBV blends. 


\subsection{Surface mechanical properties}

The advanced AM-FM mode of AFM was used for the mechanical properties analysis, and AFM images with Young's modulus distribution in a $20 \times 20 \mu \mathrm{m}^{2}$ entire surface area were obtained. The related histograms were then used for an evaluation of the mean values of Young's modulus using Gaussian fitting [19], and the values are summarized in Table 1. The AM-FM images of the untreated PLA/PHBV blends contain brighter parts associated mainly with PLA and darker parts belonging to PHBV, which was the most pronounced for 25PLA/75PHBV and 75PLA/25PHBV. The Young's modulus of the nonweathered 25PLA/75PHBV sample achieved a mean value of $1.9 \mathrm{GPa}$. The mean value of Young's modulus of 50PLA/50PHBV was the same as for 25PLA/ 75PHBV, but with a much higher distribution (peak width). The dominance of the PLA content in the 75PLA/25PHBV sample led to the highest mean values of Young's modulus (3.0 GPa), which was almost identical to that of the neat PLA standard. The accelerated weathering ageing led to the changes in mechanical properties caused by UV, thermal and hydrolytic degradation. $500 \mathrm{~h}$ of ageing time resulted in a slight increase in mechanical properties for all the prepared PLA/PHBV blends, while Young's modulus of 25PLA/75PHBV, 50PLA/50PHBV and 75PLA/25PHBV increased to $2.2 \mathrm{GPa}, 2.2$ and $3.9 \mathrm{GPa}$, respectively. The higher value of Young's modulus for $75 \mathrm{PLA} / 25 \mathrm{PHBV}$ was probably caused by a transformation of amorphous phase into crystalline

Table 1. Mechanical properties of PLA/PHBV blends collected from AFM analyses.

\begin{tabular}{|l|c|c|}
\hline \multirow{2}{*}{} & \multicolumn{2}{|c|}{$\begin{array}{c}\text { Young's modulus } \\
\text { [GPa] }\end{array}$} \\
\cline { 2 - 3 } & Mean & Width \\
\hline PLA & 2.9 & 0.5 \\
\hline PHBV & $1.8 \cdot 10^{-3}$ & $1.0 \cdot 10^{-4}$ \\
\hline $75 \mathrm{PLA} / 25 \mathrm{PHBV} / 0 \mathrm{~h}$ & 3.0 & 0.4 \\
\hline 75PLA/25PHBV/500h & 3.9 & 0.5 \\
\hline 75PLA/25PHBV/1000h & 3.9 & 0.6 \\
\hline 50PLA/50PHBV/0h & 2.7 & 0.5 \\
\hline 50PLA/50PHBV/500h & 1.9 & 0.4 \\
\hline 50PLA/50PHBV/1000h & 2.2 & 0.2 \\
\hline 50PLA/50PHBV/2000h & 2.1 & 0.4 \\
\hline 25PLA/75PHBV/0h & 2.0 & 0.4 \\
\hline 25PLA/75PHBV/500h & 1.9 & 0.2 \\
\hline 25PLA/75PHBV/1000h & 2.2 & 0.3 \\
\hline 25PLA/75PHBV/2000h & 2.2 & 0.5 \\
\hline
\end{tabular}

as was also confirmed by XRD and DSC measurements. After $1000 \mathrm{~h}$ of accelerated weathering the mechanical properties of the surfaces of 25PLA/ $75 \mathrm{PHBV}$ or $75 \mathrm{PLA} / 25 \mathrm{PHBV}$ were unchanged, and Young's modulus of 50PLA/50PHBV decreased only slightly to $2.1 \mathrm{GPa}$. $2000 \mathrm{~h}$ of ageing time of 25PLA/ $75 \mathrm{PHBV}$ resulted in an increase in the Young's modulus (2.5 GPa), as PHBV degraded and also acted as nucleating agent for the PLA crystallization, while the mean values of Young's modulus slightly decreased for 50PLA/50PHBV (2.0 GPa) and 75PLA/25PHBV $(2.7 \mathrm{GPa})$. A chain scission occurred during the degradation, preferably in the amorphous region, and crystalline domains could form [20]. The lowest values of Young's modulus were observed after 1000 and $2000 \mathrm{~h}$ of accelerated wethering of 50PLA/50PHBV, corresponding with the mechanical properties in the bulk (see Section 3.9). However, using the AM-FM mode, the values of Young's modulus were different from those determined during tensile tests. From the close values of Young's modulus before and after accelerated weathering for all the PLA/PHBV blends, it can be concluded that the degradation effect in the small surface area was insignificant compared to the degradation effect in the whole bulk considering the overall structural defects such as cracks and voids caused by thermal, UV and hydrolytic degradation.

\subsection{XRD studies}

Figure 4 shows the diffraction patterns of neat PLA, neat PHBV and the studied blends. X-ray diffraction measurements were performed for the non-weathered and weathered samples.

The non-weathered PLA/PHBV blends exhibited the characteristic profiles of each individual polymer. The spectrum obtained for neat PHBV exhibited two prominent peaks at approximately $2 \theta=19.6$ and $21.7^{\circ}$, as well as a number of minor peaks at approximately $2 \theta=22.5,22.6,28.7$ and $28.7^{\circ}$, that correspond to the reflections of the (021), (101), (111), (121), (040) crystalline planes, respectively [13, 21]. PLA shows a contrasting profile, exhibiting a broad peak between $2 \theta=7$ and $40^{\circ}$, which confirms the highly amorphous nature of PLA $[12,22]$. Two strong diffraction peaks are observed in the 25PLA/75PHBV blend, in addition to the other small peaks characteristic of PHBV, while these peaks are less prominent in the $75 \mathrm{PLA} / 25 \mathrm{PHBV} / 0 \mathrm{~h}$ blend where the broad halo from PLA is more visible. These results are expected because of the PLA and PHBV ratios. 

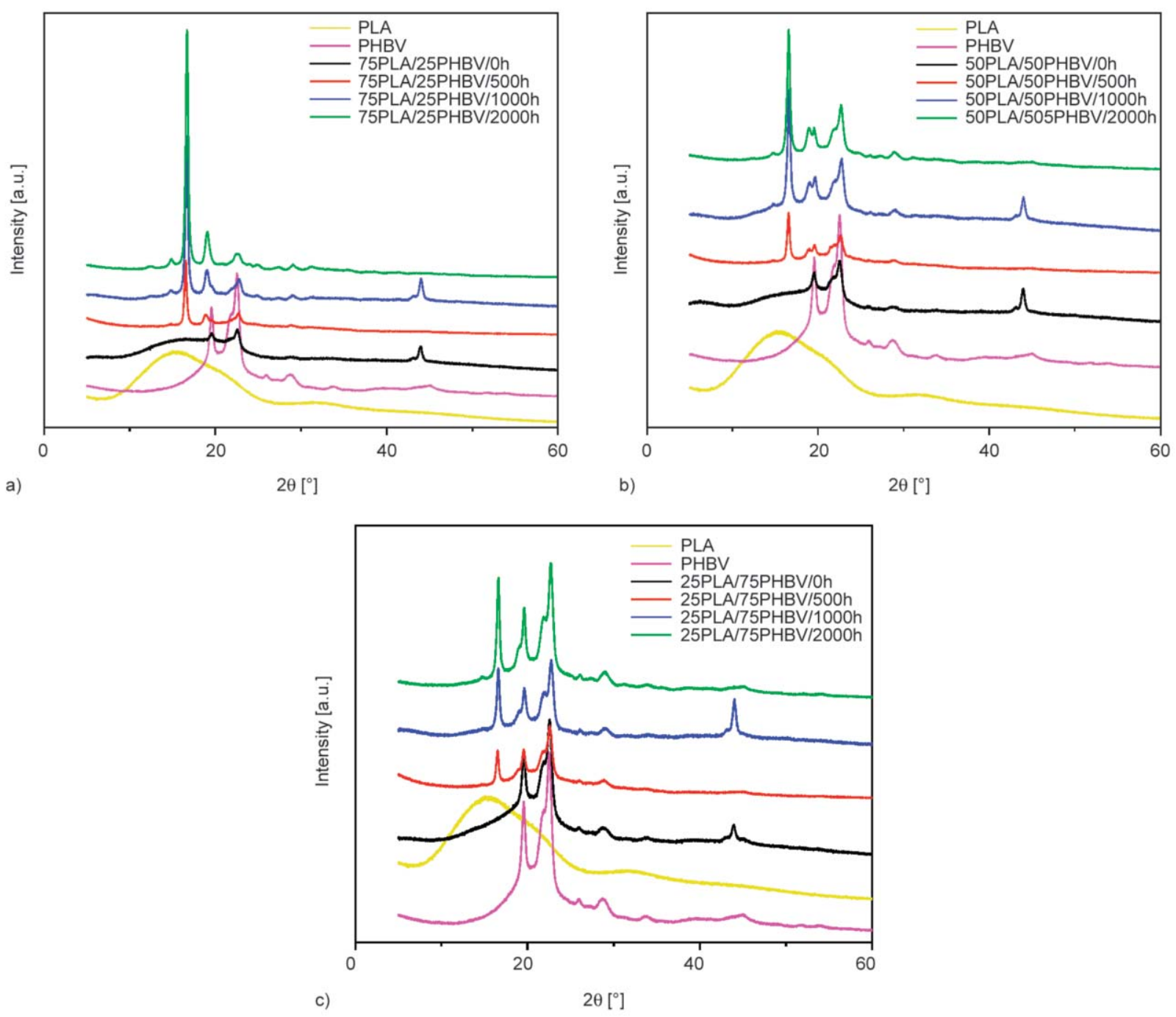

Figure 4. X-ray diffraction spectra of neat PLA, neat PHBV and a) 75PLA/25PHBV, b) 50PLA/50PHBV and c) 25PLA/ $75 \mathrm{PHBV}$ blends before and after accelerated weathering.

No recognizable new peak is observed, which confirms the immiscibility of the polymers in these blends and assuming the PLA does not crystallize when blended with PHBV. The crystalline peaks in the XRD spectra of the non-weathered blends can only be related to the PHBV crystals.

After $500 \mathrm{~h}$ of accelerated weathering an interesting change was observed in all the blends. The characteristic peak from PHBV around $2 \theta=44.0^{\circ}$ disappears and is replaced by a diffraction peak at $2 \theta=$ $16.5^{\circ}$, which corresponds to the $(110 / 200)$ planes from the crystalline structure of PLA $[6,22]$. This result indicates the development of a certain crystallinity degree in the PLA phase after weathering exposure. This confirms that the amorphous regions are being attacked during UV and hydrolytic degradation, followed by crystallization of the shorter chains and the formation of a crystalline phase. This behavior was expected after $1000 \mathrm{~h}$ [12]. However, the presence of PHBV should be the reason for the advanced degradation observed in this work, already noted after $500 \mathrm{~h}$. Three factors enhance this process. The first one is the lower resistance of PHBV than PLA to weathering degradation, which in itself supports the degradation of the blend $[12,13]$. The high mobility of the shorter chains formed during UV and moisture attack accelerated the crystallization process. The second factor is the nucleating effect of PHBV crystals in the PLA matrix [3]. In addition, it is known that the presence of free carboxylic acid end groups from the weathering degradation of PHBV could also act as a catalyst for the hydrolytic degradation of both polyesters [23].

The XRD profiles of the 25PLA/75PHBV blends after UV and moisture exposure showed the same peaks but with less prominent intensities. The 
presence of the higher content of PHBV discouraged the crystal formation of PLA around the PHBV particles. Thus, the crystallinity of the 25PLA/75PHBV blend is significantly reduced, which agrees with the percentage of PHBV crystallinity obtained and further discussed in the DSC section. After weathering exposure of the 25PLA/75PHBV blend and the formation of the PLA crystal assigned at $2 \theta=16.5$ and $18.7^{\circ}$, no changes were observed in the crystallinity of the PHBV fraction, which means that the small PLA spheres in this blend obviously did not have any observable influence on PHBV crystallization. Furthermore, the peak at $2 \theta=44.0^{\circ}$ was again observed for higher weathering exposure times. Clearly, this crystal conformation seems to be unstable and the weathering degradation affects its presence.

A slight reduction in the relative intensity of the diffraction peak of PHBV is detected as a consequence of the dilution effect of the amorphous halo from PLA. In addition, PLA will always show a more prominent crystallization process during degradation due to its amorphous character, while PHBV was already a semi-crystalline polymer before sample preparation and weathering exposure. A semi-crystalline polymer is composed of an impermeable crystalline phase dispersed in a permeable amorphous phase. Crystallites offer a physical barrier to water and UV penetration, increasing the tortuosity transport path for these degradation agents, while the amorphous phase offers a permeable way [5]. Thus,
PLA offers less resistance to UV and water permeation, which means PLA will have this additional step during degradation. This should be the reason why the PLA fraction is degraded later than PHBV. The incorporation of a large amount of PLA can therefore be considered as a UV and moisture barrier during the degradation process of the PLA/PHBV blends.

No effect was also detected in the blends' crystalline morphologies after long weathering exposure. Therefore, it can be concluded that the crystalline morphology of PLA and PHBV is not affected by the presence of the other one, proving their immiscible nature, but could be enhanced during weathering degradation.

\subsection{Surface energy}

Contact angle measurements were carried out to evaluate the hydrophilic/hydrophobic character of the PLA/PHBV blends before and after accelerated weathering degradation. It is known that a hydrophilic property enhances the polymer surface wettability, allowing it to hydrolytically degrade during the weathering exposure. Thus, cracks, holes and voids appear earlier allowing the bulk of the sample to also be exposed to water diffusion and UV penetration. These results are shown in Table 2. The contact angles of $25 \mathrm{PLA} / 75 \mathrm{PHBV} / 2000 \mathrm{~h}$ could not be determined because its surface was completely degraded as observed in Figure 1, thus it was not possible to correctly assess this value.

Table 2. CAs of water, formamide and ethylene glycol and surface energy in PLA/PHBV blends before and after accelerated weathering.

\begin{tabular}{|l|c|c|c|c|c|c|}
\hline \multirow{2}{*}{} & \multicolumn{3}{|c|}{$\begin{array}{c}\text { CA } \\
\text { [ }{ }^{2}\end{array}$} & \multicolumn{2}{c|}{$\begin{array}{c}\text { SE } \\
\text { [m/m] }\end{array}$} \\
\cline { 2 - 7 } & Water & Formamide & Ethylene glycol & Total surface energy & Dispersive component & Polar component \\
\hline PLA & $66.9 \pm 0.8$ & $49.5 \pm 1.8$ & $56.2 \pm 2.0$ & 36.5 & 8.4 & 28.1 \\
\hline PHBV & $72.7 \pm 1.4$ & $53.5 \pm 0.9$ & $54.1 \pm 0.8$ & 32.9 & 15.4 & 17.5 \\
\hline 75 PLA/25PHBV/0h & $76.8 \pm 1.6$ & $63.1 \pm 3.4$ & $55.5 \pm 1.1$ & 30.4 & 25.5 & 8.9 \\
\hline 75PLA/25PHBV/500h & $53.8 \pm 1.1$ & $38.9 \pm 1.3$ & $30.4 \pm 2.5$ & 45.6 & 14.1 & 31.5 \\
\hline 75PLA/25PHBV/1000h & $46.8 \pm 1.5$ & $29.1 \pm 2.1$ & $30.3 \pm 1.9$ & 52.3 & 9.5 & 42.8 \\
\hline 75PLA/25PHBV/2000h & $31.8 \pm 1.1$ & $23.8 \pm 2.2$ & $19.7 \pm 2.0$ & 65.6 & 4.9 & 60.7 \\
\hline 50PLA/50PHBV/0h & $69.2 \pm 1.9$ & $39.2 \pm 1.2$ & $41.4 \pm 3.1$ & 47.1 & 42.5 & 4.6 \\
\hline 50PLA/50PHBV/500h & $65.5 \pm 1.3$ & $40.6 \pm 2.4$ & $41.6 \pm 0.9$ & 39.9 & 20.0 & 19.9 \\
\hline 50PLA/50PHBV/1000h & $51.1 \pm 1.9$ & $32.8 \pm 1.9$ & $35.7 \pm 1.4$ & 48.9 & 9.5 & 39.2 \\
\hline 50PLA/50PHBV/2000h & $23.9 \pm 2.3$ & $21.2 \pm 1.1$ & $3.71 \pm 3.2$ & 77.2 & 2.4 & 74.8 \\
\hline 25PLA/75PHBV/0h & $69.8 \pm 1.1$ & $55.9 \pm 2.8$ & $58.1 \pm 3.1$ & 33.0 & 13.3 & 19.7 \\
\hline 25PLA/75PHBV/500h & $63.8 \pm 1.5$ & $39.3 \pm 1.3$ & $45.8 \pm 1.9$ & 39.7 & 14.7 & 25.0 \\
\hline 25PLA/75PHBV/1000h & $53.4 \pm 1.6$ & $30.2 \pm 1.2$ & $33.9 \pm 1.9$ & 47.1 & 13.1 & 34.0 \\
\hline 25PLA/75PHBV/2000h & - & - & - & - & - & - \\
\hline
\end{tabular}


Both neat polymers presented static values for $C A_{\text {water }}$ higher than $65^{\circ}[12,13,24]$. Thus, it was expected that all the formulations would show values higher than $65^{\circ}$ for $C A_{\text {water }}$ before weathering. For instance, the presence of higher PLA content in 75PLA/ 25PHBV blend resulted in a slight increase in hydrophobic character of the blend's surface. 75PLA/ $25 \mathrm{PHBV} / 0 \mathrm{~h}$ showed a $C A_{\text {water }}=76.8^{\circ}$ compared to 50PLA/50PHBV/0h and 25PLA/75PHBV/0h blends, respectively $69.2^{\circ}$ and $69.8^{\circ}$. The hydrophobicity of the samples should increase with PHBV content since PHBV are naturally more hydrophobic than PLA due to its methyl side groups, but it also contains polar oxygen linkages, which confer hydrophilic properties to the polymer. In addition, it is known that longer carbon chain length enhances the hydrophobicity of the polyester [25]. The first stage of degradation of a polyester chain is usually the reduction of its molecular weight that occurs by random cleavage of the ester bonds decreasing the polymer chain length. During the blending and fabrication process of the blends at high temperatures, polymers are exposed to thermal degradation $[8,26]$. Since PHBV has a lower melting temperature than PLA, the $C A$ results strongly suggest that chain scissions randomly occurred preferentially in the molecules of PHBV. Therefore, the lower $C A_{\text {water }}$ in 50PLA/ $50 \mathrm{PHBV} / 0 \mathrm{~h}$ and 25PLA/75PHBV/0h blends confirm the degradative chain scission of the samples. Meanwhile, the wettability performance of the material is not only strongly dependent on the chemical properties of the surface, but also on the topography of the material. The $C A_{\text {water }}$ of neat PLA $\left(66.9^{\circ}\right)$ is slightly lower than that in 75PLA/25PHBV $\left(75.0^{\circ}\right)$, which is similar to that of $\mathrm{PLA} / \mathrm{TiO}_{2} / 0 \mathrm{~h}$ as reported in our previous work [12]. This should be related to the synergistic effect of some crystallinity from the presence of a low content of PHBV, which contributed to a less smooth surface than the neat polymer, such as was observed in the presence of nanofillers [12].

A gradual and constant decrease of the $C A_{\text {water }}$ was observed for all the blends over the weathering exposure. During polymer degradation, free radicals are generated, reacting with ambient oxygen to produce peroxide groups. These compounds decompose and give rise to a variety of polar groups, such as hydroxyl, carbonyl, and carboxylic acid [27], which should be the reason for the observed continuous increase of the polar component and surface energy of all the blends over the exposure time, corroborating with the FTIR results discussed in the next section. A gradual decrease of the $C A_{\text {water }}$ was also observed for $C A_{\text {ethylene glycol }}$ and $C A_{\text {formamide. In addition, lower }}$ values were observed for the $C A$ s of the non-weathered and weathered 50PLA/50PHBV and 25PLA/ 75PHBV blends, while a sharp drop was observed for $75 \mathrm{PLA} / 25 \mathrm{PHBV}$. The most significant change was noticed for $75 \mathrm{PLA} / 25 \mathrm{PHBV} / 500 \mathrm{~h}$ in which $C A_{\text {water }}$ was $53.8^{\circ}$, giving a decrease of approximately $30^{\circ}$. 50PLA $/ 50 \mathrm{PHBV} / 500 \mathrm{~h}$ and $25 \mathrm{PLA} / 75 \mathrm{PHBV} /$ $500 \mathrm{~h}$ blends increased the hydrophilicity of their surfaces just around $5^{\circ}$. As well as the chemical composition of each material, cracks and holes on the surface also contribute to the surface energy. The physical changes observed during degradation increased the roughness, and this also contributed to the increase in the hydrophobicity of the most damaged blends, i.e., 25PLA/75PHBV and 50PLA/50PHBV compared to 75PLA/25PHBV [7]. Thus, the combination of chemical and physical degradation contributes to the surface properties of the weathered samples. In addition, some authors mentioned that the larger contact angle of a hydrophobic surface can be related to an increase in surface roughness, whereas the contact angle of a hydrophilic surface decreases with increasing roughness of the polymer sample after a degradation process [28]. Thus, the increased wettability and surface degradation self-stimulates the continued weathering degradation.

\subsection{Surface chemistry (FTIR)}

Figure 5 shows the FTIR-ATR spectra of the PLA/ PHBV blends and the corresponding neat polymers from 4000 to $500 \mathrm{~cm}^{-1}$. The same figure also shows the infrared spectra of each blend after 500, 1000 and $2000 \mathrm{~h}$ of the accelerated weathering.

In addition to the main characteristic peaks of PLA and PHBV $[12,13]$ exhibited in the FTIR-ATR spectra of the PLA/PHBV blends, only small changes are noticed due to the overlapped bands and the different ratios of each polymer. The spectra of the 75PLA/ 25PHBV, 50PLA/50PHBV and 25PLA/75PHBV blends were very similar to those of the neat polymers, which confirmed that PLA and PHBV are immiscible in these blends and there is no strong molecular interaction between them.

Since differences in the initial crystallinity of polymers should be considered, neat PLA is primarily amorphous, whereas neat PHBV is semi-crystalline. 
Thus, the $\mathrm{C}=\mathrm{O}$ band widths for PLA and PHBV differed significantly. FTIR spectra showed a broad peak at $1746 \mathrm{~cm}^{-1}$ which corresponds to the amorphous carbonyl stretching vibration of the PLA fraction and remains constant in all the non-weathered blends. To more clearly observe the change in $\mathrm{C}=\mathrm{O}$ peaks, the bands at $1850-1650 \mathrm{~cm}^{-1}$ are zoomed in Figure 5. This characteristic peak of PLA is obviously detected in the 75PLA/25PHBV/0h blend, but less prominent in the 50PLA/50PHBV/0h and 25PLA/ $75 \mathrm{PHBV} / 0 \mathrm{~h}$ blends. A broad band centred at $1713 \mathrm{~cm}^{-1}$ and attributed to the carbonyl stretching of the PHBV fraction was also observed in the FTIR spectra of the PLA/PHBV blends before weathering. The intensity ratio of these two bands was noticed to change with composition ratio of each polymer in the blends. While 75PLA/25PHBV/0h exhibited a shoulder at $1713 \mathrm{~cm}^{-1}$, it was observed to be sharp in the 50PLA/50PHBV $/ 0 \mathrm{~h}$ and $25 \mathrm{PLA} / 75 \mathrm{PHBV} / 0 \mathrm{~h}$ blends with increasing PHBV content.

Subtle changes were observed, such as a small shift to higher wavenumbers in the carbonyl $\mathrm{C}=\mathrm{O}$ peak of PLA for the FTIR spectrum of 75PLA/25PHBV/ $500 \mathrm{~h}$, which was more clearly identified in each blend over the weathering exposure. During the degradation process, shorter polymer chains are easily able to re-organize into crystalline domains. In addition, the lower glass transition temperature of PHBV (around $-47^{\circ} \mathrm{C}$ ) and the $50{ }^{\circ} \mathrm{C}$ of the weathering cycles much more promote this polymer rearrangement. As crystallization increases, these values may shift/split due to higher crystalline perfection [29], which was clearly observed in 75PLA/25PHBV/ 2000h. This sample shows a broadened carbonyl peak at $1755 \mathrm{~cm}^{-1}$. The simplest way to observe the differences is that the crystallinity of the PLA samples

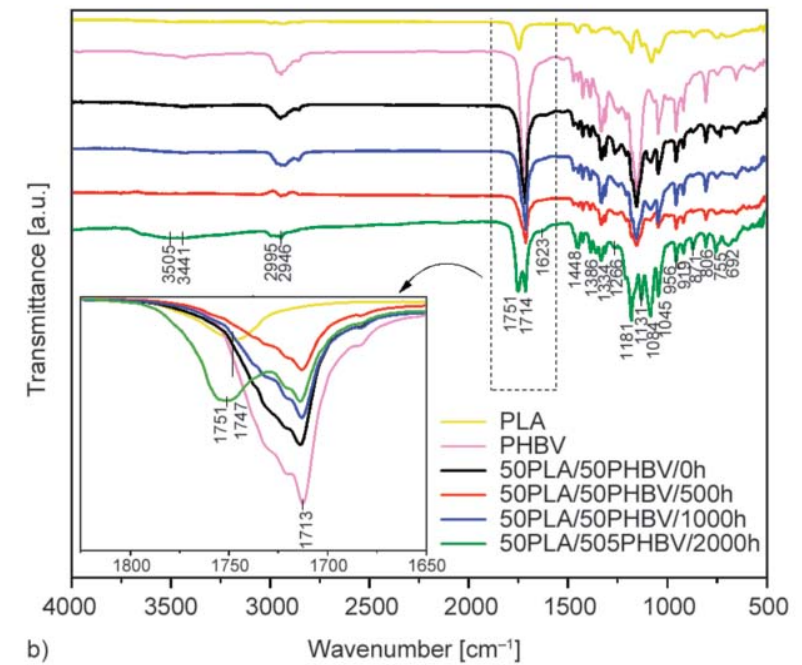

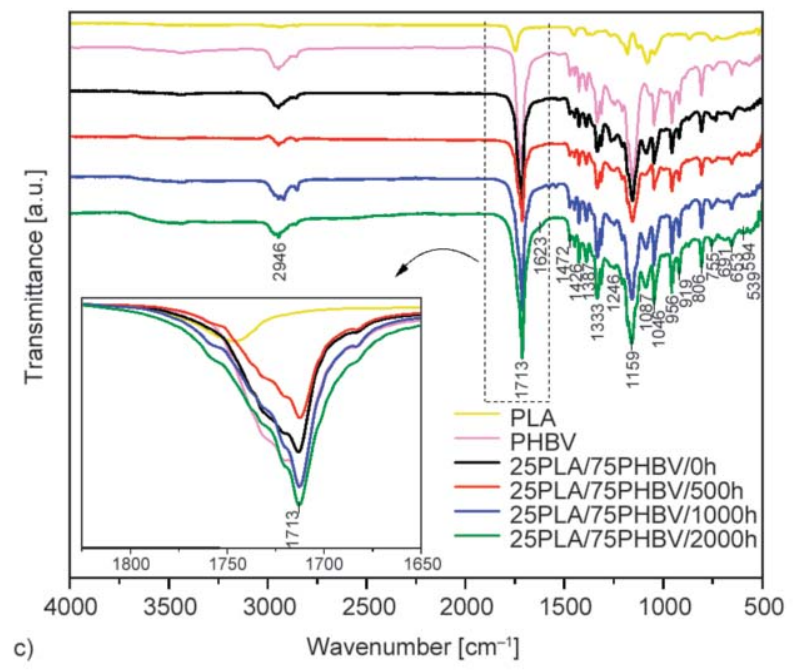

Figure 5. FTIR spectra of neat PLA, neat PHBV and a) 75PLA/25PHBV, b) 50PLA/50PHBV and c) 25PLA/75PHBV blends before and after accelerated weathering. 
relies on the area of an amorphous band at $955 \mathrm{~cm}^{-1}$. During crystallization, the intensity of this band should decrease and a new band should appear at $921 \mathrm{~cm}^{-1}$ [29]. However, both bands are also present in the neat PHBV spectra resulting in both bands being visible in the blends before any degradation, which does not allow any conclusion about differences in the PLA crystallinity. After $2000 \mathrm{~h}$ of weathering, an additional new shoulder was noticed at $1654 \mathrm{~cm}^{-1}$ from the photodegradation of the PLA fraction according to a Norrish II mechanism of carbonyl polyester which involves chain cleavage and the presence of a hydroperoxide and $\mathrm{C}=\mathrm{C}$ double band [4].

Figure 5 indicates major changes in the structure of the 50PLA/50PHBV blends over the weathering time. A decrease in the carbonyl stretching at $1713 \mathrm{~cm}^{-1}$ was observed, indicating the weathering attack on the PHBV structure leading to the $\mathrm{C}=\mathrm{O}$ groups' consumption, with an increase in the intensity of the $\mathrm{C}=\mathrm{O}$ peak for PLA at $1751 \mathrm{~cm}^{-1}$, which was overlapped in the non-weathered samples. This wavenumber showed a shift to higher values after weathering, indicating the modification of the PLA structure as previously discussed. The new shoulder at $1653 \mathrm{~cm}^{-1}$ that corresponds to the formation of $\mathrm{C}=\mathrm{C}$ groups observed in 75PLA/25PHBV was also observed in the 50PLA/50PHBV and 25PLA/75PHBV blends around $1623 \mathrm{~cm}^{-1}$. It seems to happen only after $2000 \mathrm{~h}$ of weathering, independent of the blend composition.

Analyzing the carbonyl content of the 25PLA/ $75 \mathrm{PHBV}$ samples, a strong peak at $1713 \mathrm{~cm}^{-1}$ related to the crystalline vibration of PHBV was observed to become more prominent over the degradation time. On the other hand, the PLA carbonyl vibration was not visible. At the same time the wavenumber range at $1800-1600 \mathrm{~cm}^{-1}$ assigned to the carbonyl content was broader after $2000 \mathrm{~h}$, which could suggest an increase of $\mathrm{C}=\mathrm{O}$ from the PLA phase and the suppressed peak from PHBV around $1159 \mathrm{~cm}^{-1}$, observed in the 50PLA/50PHBV blend. This increased over time in the blend with $75 \mathrm{wt} . \%$ of PHBV.

Additionally, an intense broad band in the wavenumber range $3300-3500 \mathrm{~cm}^{-1}$ was noticed for all the PLA/PHBV blends after $2000 \mathrm{~h}$ of weathering exposure, which should be attributed to $-\mathrm{OH}$ stretching. The weathering degradation promotes an increase in hydroxyl containing groups confirming the polar properties of the surface already elucidated in the wettability analysis and revealed by FTIR.

\subsection{Thermal properties}

DSC analysis was used to follow changes caused by weathering degradation in blends of PLA/PHBV. The related data from the DSC analysis (melting and cold crystallization enthalpy and temperature, glass transition and degree of crystallinity respectively, $\Delta H_{\mathrm{m}}, \Delta H_{\mathrm{cc}}, T_{\mathrm{m}}, T_{\mathrm{cc}}, T_{\mathrm{g}}$ and $X_{\mathrm{C}}$ ) for each component in the blends are summarized in Table 3.

The 75PLA/25PHBV/0h blend showed an intense broad cold crystallization peak at $110^{\circ} \mathrm{C}$, and the intensity decreased for 50PLA $/ 50 \mathrm{PHBV} / 0 \mathrm{~h}$ (observed at $113^{\circ} \mathrm{C}$ ), while it was quasi-inexistent in the 25PLA/75PHBV/0h blend. Comparing the enthalpy values in Table 3 , it is clear that the PHBV crystals acted as nucleation centers for the cold crystallization of PLA during sample preparation $[3,5,18]$. This event was not observed in the XRD analysis before weathering, which should be justified by the low crystal content in these samples. The cold crystallization peaks are much more intense and well resolved at lower content of PHBV in the blends.

The absence of cold crystallization of PLA was also noted in all the blends after weathering. The chain segments after weathering scission became too short to properly arrange into crystallites.

A narrow melting peak was observed around $92^{\circ} \mathrm{C}$ in the $25 \mathrm{PLA} / 75 \mathrm{PHBV} / 0 \mathrm{~h}$ blend. The presence of the second melting peak around $80^{\circ} \mathrm{C}$ of the PHBV fraction was more pronounced as the PHBV content increased in the blends and over the weathering exposure time. This melting peak of PHBV was difficult to observe in the blend with $75 \mathrm{wt} \%$ PLA content, because it is overlapped with the of $T_{\mathrm{g}}$ of PLA, which is well observed in the presence of 75 and $50 \mathrm{wt} \%$ of PLA and less pronounced in the 25PLA/ 75PHBV blends.

As expected, the melting peak of PLA is much more pronounced in the blend which contains a higher amount of PLA. However, a double melting peak in the $140-150^{\circ} \mathrm{C}$ temperature region is clearly observed at 147 and $151^{\circ} \mathrm{C}$ in the 25PLA/75PHBV/0h blend. The double melting peak for PLA could reflect the melting of $\beta$ and $\alpha$-crystallites, that have different melting temperatures due to different size and perfection [30]. However, it could also have been the result of a melting-recrystallization-melting process, or of the melting of different sized lamellae formed 


\begin{tabular}{|c|c|c|c|c|c|c|c|c|c|c|c|c|c|c|}
\hline 通㝴 & 01 & 1 & 으 & ๗ె & ఉా & ₹ & $\infty$ & $\bar{m}$ & $\bar{m}$ & q & $=$ & ते & ते & $\hat{m}$ \\
\hline 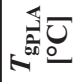 & \begin{tabular}{l|l}
$\vec{a}$ & \\
in &
\end{tabular} & $1 \bar{c}$ & $\overrightarrow{.}$ & $\frac{m}{n}$ & $\frac{n}{n}$ & 1 & $\begin{array}{l}\text { ra } \\
\text { in }\end{array}$ & ì & $\begin{array}{l}\text { Y } \\
\stackrel{\leftrightarrow}{n} \\
\text {. }\end{array}$ & 1 & $\begin{array}{l}0 \\
\dot{\sim} \\
i n\end{array}$ & in & 1 & 1 \\
\hline 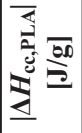 & $\stackrel{\sim}{i}$ & 1 & $n$ & 1 & 1 & 1 & $\begin{array}{l}\infty \\
\dot{+}\end{array}$ & 1 & 1 & 1 & $\stackrel{\circ}{-}$ & 1 & 1 & 1 \\
\hline 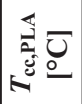 & $\stackrel{\stackrel{I}{I}}{\stackrel{I}{S}}$ & 1 & : & 1 & 1 & 1 & $\begin{array}{l}0 \\
\stackrel{i}{\Xi} \\
=\end{array}$ & 1 & 1 & 1 & ㅇ. & 1 & 1 & 1 \\
\hline 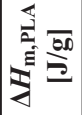 & $\stackrel{n}{\sim}$ & 1 & ¿ें. & 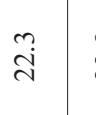 & సे & तें & $\stackrel{ナ}{\oplus}$ & $\stackrel{?}{ \pm}$ & $\begin{array}{l}\infty \\
\vdots \\
i \\
\end{array}$ & $\begin{array}{l}\stackrel{\infty}{\infty} \\
\stackrel{\infty}{ }\end{array}$ & 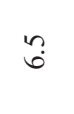 & $\stackrel{\infty}{\circ}$ & $\stackrel{\infty}{\infty}$ & $\underset{\infty}{0}$ \\
\hline Uె口 & 咅 & 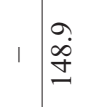 & $\begin{array}{ll}m \\
\dot{t} \\
i\end{array}$ & $\begin{array}{ll}0 & 2 \\
\stackrel{\circ}{n} & \stackrel{n}{n}\end{array}$ & 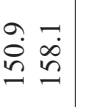 & ֶֶّ & $\dot{\partial}$ & ڤે & $\vec{n}:$ & $\begin{array}{l}n \\
\dot{a} \\
g\end{array}$ & 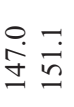 & $\frac{n}{n}$ & $\hat{\tilde{n}}$ & $\overrightarrow{\stackrel{\infty}{9}}$ \\
\hline 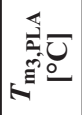 & & 1 & 1 & 1 & $\stackrel{n}{m}$ & 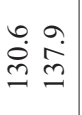 & I & $\stackrel{n}{m}$ & 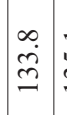 & $\overrightarrow{\stackrel{\dot{a}}{a}}$ & I & 1 & 1 & ?ֶ. \\
\hline 辤递 & 1 in & $\stackrel{\overbrace{}}{i}$ & ते & 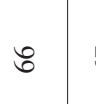 & $\tilde{6}$ & 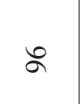 & $\stackrel{\infty}{\sim}$ & f & $\overrightarrow{6}$ & 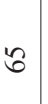 & $m$ & $\tilde{n}$ & in & 6 \\
\hline 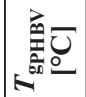 & 19 & \begin{tabular}{c|c}
$\frac{3}{4}$ & $?$ \\
$y$ & 7
\end{tabular} & $\frac{?}{q}$ & $\begin{array}{l}\dot{U} \\
\dot{Z}\end{array}$ & $\dot{u}$ & $\dot{u}$ & के & 巳̊ & $\stackrel{\circ}{\dot{y}}:$ & $\stackrel{\sim}{\dot{p}}$ & $\begin{array}{l}\infty \\
\stackrel{y}{y}\end{array}$ & $\stackrel{\stackrel{Y}{F}}{\bar{y}}$ & $\stackrel{\infty}{\dot{p}}$ & $\begin{array}{l}0 \\
\dot{p} \\
\dot{p}\end{array}$ \\
\hline 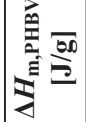 & $\mid$\begin{tabular}{l|l}
$\infty$ & $\infty$ \\
$\infty$ & $\infty$
\end{tabular} & $\begin{array}{l}\infty \\
\infty \\
\infty \\
\infty\end{array}$ & $\stackrel{\circ}{\infty}$ & $\vec{\infty}$ & $\stackrel{m}{\infty}$ & సु. & $\mid \begin{array}{l}n \\
n \\
n \\
n\end{array}$ & $\stackrel{\text { ָे }}{\tilde{y}}$ & m: & $\begin{array}{l}n \\
\ddot{n} \\
m\end{array}$ & $\stackrel{m}{\stackrel{n}{N}}$ & $\ddot{q}$ & $\begin{array}{l}\infty \\
\dot{\alpha} \\
\dot{q}\end{array}$ & in \\
\hline 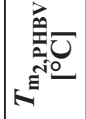 & $1 \frac{n}{\sigma}$ & 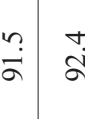 & ָ̇ & $\begin{array}{l}\dot{\sigma} \\
\dot{a}\end{array}$ & ๙ू. & 1 & ळे & $\stackrel{\infty}{\Omega}$ & 檪 & $\vec{\infty}$ & ָ̇i & $\bar{n}$ & हू & 1 \\
\hline 兽 & & $\begin{array}{l}0 \\
\text { فे }\end{array}$ & $1 \mid \begin{array}{lll}n \\
\end{array}$ &  & $\stackrel{\infty}{i}$ & $\vec{\infty}$ & $\stackrel{\substack{\infty \\
\infty}}{\infty}$ & 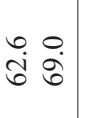 & त̂: & $\stackrel{\sim}{\stackrel{+}{\sim}}$ & $\stackrel{n}{\stackrel{n}{r}}$ & 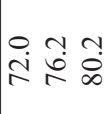 & 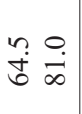 & 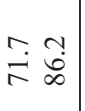 \\
\hline & 岕盖 & 离 & 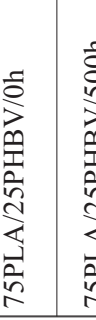 & 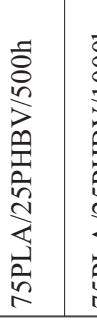 & 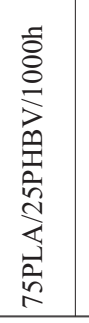 & 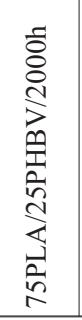 & 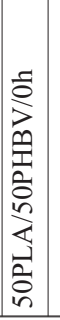 &  & 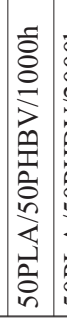 & 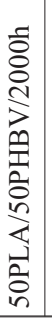 & 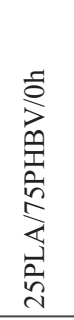 & 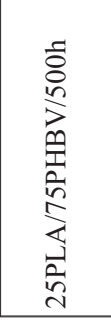 & 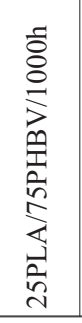 & 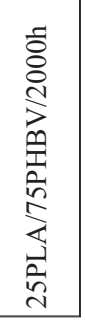 \\
\hline
\end{tabular}


during the blending of a low content of PLA in a matrix of PHBV [31].

Table 3 shows that the $T_{\mathrm{cc}}$ increased but the enthalpy decreased for PLA in the 75PLA/25PHBV/0h and 50PLA/50PHBV/0h blends, respectively, although the $T_{\mathrm{m} 3}$ and $T_{\mathrm{m} 4}$ did not change. There were no significant changes in the main melting peak of each polymer with an increase in weathering time up to $1000 \mathrm{~h}$ in the three blends. The inconsistent changes in the $T_{\mathrm{g}}$ of PLA with increasing weathering time may have been caused by a complex influence of factors like changes in free volume and the configuration of the amorphous phase on this parameter [32,33]. In addition, the $T \mathrm{~g}$ of PLA in the 25PLA/75PHBV/ 1000h, 25PLA/75PHBV/2000h, 50PLA/50PHBV/ $2000 \mathrm{~h}$ and $75 \mathrm{PLA} / 25 \mathrm{PHBV} / 2000 \mathrm{~h}$ blends was not observed due to the overlapped endothermic peak of $T_{\mathrm{m} 1}$. The broadness in the melting peaks is related to the broadening in the distribution of the polymer chain lengths, i.e., having both long and short chains at the same time after degradation. In addition, a small shoulder at a lower temperature (around $65^{\circ} \mathrm{C}$ ) can be noticed in all the blends after 500 and $1000 \mathrm{~h}$ of weathering, which possibly reflects a small quantity of very low $M_{\mathrm{w}}$ polymer as a result of chain scission during degradation. As in the case of PHBV, PLA also shows a new small peak around $135^{\circ} \mathrm{C}$ attributed to the formation of PLA with lower $M_{\mathrm{w}}$ and new crystals after degradation.

A slight decrease in the melting temperature of PLA and PHBV was noticed in all the blends after $2000 \mathrm{~h}$ of weathering. It is clear that the $75 \mathrm{PLA} / 25 \mathrm{PHBV} /$ $2000 \mathrm{~h}$ blend was the sample showing the most significant structural changes, as observed in Figure 1 from the infinite number of voids on the surface indicating huge damages in matrix cohesiveness. It is demonstrated by large and broad peaks featured by different thermal stabilities due to differently sized and imperfect crystallites.

Whatever the PHBV content in the blend, the $X_{\mathrm{c}, \text { PLA }}$ for the non-weathered blends were very similar within experimental error, 10,8 and $11 \%$, as also observed for the PHBV fraction. On the other hand, an increase in the crystallinity degree of both fractions is clearly observed with increasing weathering time. This behavior was much more pronounced for a low PHBV content in the blend. While Table 3 shows an $X_{\mathrm{c}, \mathrm{PHBV}}$ of $63 \%$ for $25 \mathrm{PLA} / 75 \mathrm{PHBV} / 2000 \mathrm{~h}, 75 \mathrm{PLA} /$ 25PHBV/2000h was almost completely crystalline $(96 \%)$. There is no single explanation for this result.
Several events happen at the same time during weathering degradation, such as hydrolysis and UV attack, chain scission of the amorphous regions in PLA and PHBV, as well as the degradation of the crystalline regions. One possible explanation is the initial amorphous character of the PLA. It is susceptible to degradation, leading to chain rearrangement of this phase into a semi-crystalline structure which acted as barrier against weathering degradation of the PHBV matrix. In contrast, when PHBV is moisture and UVattacked, both amorphous and crystalline regions are available to be degraded. The crystallinity degree of PLA decreased for lower PLA content in the blends. This can suggest that PHBV in the blend hinders the crystallization of PLA when a high ratio of PHBV was present, possibly protecting them from degradation. Another reason which has been proposed is that the difference in melting temperature was large enough for the higher $T_{\mathrm{m}}$ component to crystallize first and for its spherulites to fill the whole volume, while the component with lower $T_{\mathrm{m}}$ crystallizes at a lower temperature in a space limited region inside the existing spherulites [34].

The presence of the PLA in the PHBV matrix showed fluctuating values for the temperature and rate of crystallization over the exposure time, because of the heterogeneous bulk and multiple events during the crystallization and degradation process, which was higher for the weathered samples. However, it proves the easier re-organization of the shorter polymer chains after chain scission during degradation under weathering conditions.

\subsection{Thermogravimetric analysis (TGA)}

TGA analysis was done to study the effect of accelerated weathering on the mass loss curves of the blends at constant PLA/PHBV ratios. The respective temperatures are summarized in Table 4.

PHBV degrades around $405^{\circ} \mathrm{C}$ and PLA around $365^{\circ} \mathrm{C}[12,13]$. The two polymers in the blend degraded separately confirming their immiscibility as already discussed. The first mass loss step represents the degradation of PLA and the second that of PHBV. It is known that the thermal degradation of PHBV follows a nonradical random chain scission mechanism involving a six-membered ring ester decomposition process [35]. The final degradation products of $\mathrm{PHBV}$ are $\mathrm{CO}_{2}$ and $\mathrm{H}_{2} \mathrm{O}$, while the thermal degradation of PLA involves an intramolecular transesterification leading to the formation of lactide and cyclic 
Table 4. Characteristic degradation temperatures from the dTGA peak maxima for neat PLA, neat PHBV and the PLA/PHBV blends.

\begin{tabular}{|l|c|c|}
\hline & $\begin{array}{c}\text { PLA } \\
\text { degradation step } \\
{\left[{ }^{\circ} \mathbf{C}\right]}\end{array}$ & $\begin{array}{c}\text { PHBV } \\
\text { degradation step } \\
{\left[{ }^{\circ} \mathbf{C}\right]}\end{array}$ \\
\hline PLA & 362.0 & - \\
\hline PHBV & - & 405.1 \\
\hline 75PLA/25PHBV/0h & 368.1 & $389-420$ \\
\hline 75PLA/25PHBV/500h & 370.2 & $385-420$ \\
\hline 75PLA/25PHBV/1000h & 353.7 & $380-420$ \\
\hline 75PLA/25PHBV/2000h & 364.0 & $384-416$ \\
\hline 50PLA/50PHBV/0h & 362.0 & 396.3 \\
\hline 50PLA/50PHBV/500h & 366.4 & 401.8 \\
\hline 50PLA/50PHBV/1000h & 364.2 & 397.1 \\
\hline 50PLA/50PHBV/2000h & 344.9 & 384.1 \\
\hline 25PLA/75PHBV/0h & 353.7 & 406.1 \\
\hline 25PLA/75PHBV/500h & 351.5 & 400.7 \\
\hline 25PLA/75PHBV/1000h & 345.4 & 399.6 \\
\hline 25PLA/75PHBV/2000h & 336.6 & 397.9 \\
\hline
\end{tabular}

oligomers, followed by the formation of acrylic acid from cis-elimination as well as carbon oxides and acetaldehyde from fragmentation reactions [36]. Blending PLA with PHBV increased the mass loss temperature range of the blends if the content of PHBV was low, i.e., 75PLA/25PHBV/0h presented the maximum decomposition at 368 and $406^{\circ} \mathrm{C}$, for the PLA and PHBV fractions, while 25PLA/ 75PHBV/0h started decomposing at $354^{\circ} \mathrm{C}$. As already explained, PHBV can be a nucleating agent to PLA crystallization during sample preparation, and this was probably the reason for the observed results. A slight shift to higher temperature values was noticed in $75 \mathrm{PLA} / 25 \mathrm{PHBV} / 500 \mathrm{~h}$ and 50PLA/50PHBV/ $500 \mathrm{~h}$, which indicates an increase in polymer stability as a result of the plasticizing effect of the oligomeric products generated during degradation of the PLA $[12,37]$. In addition, it is known that weathering degradation reduces the $M_{\mathrm{w}}$ of a polymer, and this is followed by the formation of crystalline domains that degraded more slowly during TGA analysis. This behavior was not observed in 25PLA/ $75 \mathrm{PHBV} / 500 \mathrm{~h}$ where the temperature of mass loss of PLA continued to decrease with increasing weathering time.

The 25PLA/75PHBV samples degraded at lower temperatures than neat PLA. When the PLA ratio in the blend was small, it could not re-organize easily to produce crystalline regions or plasticize itself. Amorphous chains are more susceptible to degradation, and this is visible in these blends. Amorphous chains from PLA could improve the thermal stability of the PHBV fraction, acting as thermal barrier against heat diffusion and degradation as previously mentioned.

As expected from the previous analyses, all the blends after $2000 \mathrm{~h}$ accelerated weathering were much more damaged and susceptible to thermal decomposition. Thus, the respective temperatures decreased significantly after $2000 \mathrm{~h}$ of exposure. Therefore, the $25 \mathrm{PLA} / 75 \mathrm{PHBV} / 2000 \mathrm{~h}$ seems to have a slightly lower thermal stability than the other blends, while an interesting result is noticed for the 50PLA/ 50PHBV blend, which seems to have been much more stable than the other polymer ratios.

\subsection{Mechanical properties}

Variations in the tensile properties, i.e., strength at break $\left(\sigma_{\text {break }}\right)$, Young's modulus $(E)$, and elongation at break $\left(\varepsilon_{\text {break }}\right)$, of the PLA/PHBV blends both before and after accelerated weathering were studied. Figure 6 presents an example of a stress-strain curve of each blend before weathering. The tensile properties for each blend after different periods of accelerated weathering are summarized in Table 5.

A significant general improvement in the tensile properties was observed for the blends compared to those of the neat polymers. The tensile strength of the blends was higher than those of the neat polymers, and PLA changed from brittle to ductile after addition of $25 \mathrm{wt} \%$ of the PHBV. The stress-strain curves of $75 \mathrm{PLA} / 25 \mathrm{PHBV} / 0 \mathrm{~h}$ and $25 \mathrm{PLA} / 75 \mathrm{PHBV} / 0 \mathrm{~h}$ (Figure 6) presented three clear regions related to elastic and plastic deformation. The first region showed linear stretching with recoverable deformation, followed by a neck formation. Then, a plastic deformation was observed in the second region, which is permanent and non-recoverable. The third region is clearly noted in $75 \mathrm{PLA} / 25 \mathrm{PHBV} / 0 \mathrm{~h}$ related to strain hardening in this blend. In this region, the strength gradually increases until the samples break. Strain hardening behavior is an interesting property which can allow higher quality products due to its good resistance against stretching of polymer segments [38]. This behavior is less prominent in 25PLA/ 75PHBV/0h.

The addition of PHBV at various loadings $(25,50$ and $75 \mathrm{wt} \%$ ) into the PLA matrix led to a reduction in the $\sigma_{\text {break }}$ and $E$, but an increase in the $\varepsilon_{\text {break }}$. This is due to PHBV which has a much lower $E$ and higher flexibility than PLA. Thus, the brittleness of PLA 


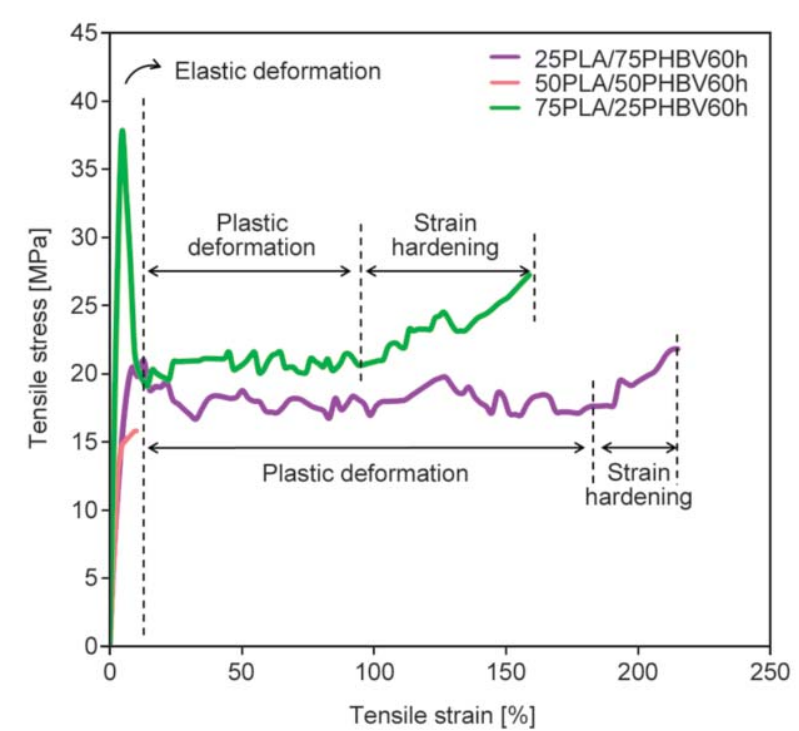

Figure 6. Representative tensile stress-strain curves of each blend before exposure to accelerated weathering.

was reduced by the decrease in the $E$ achieving 1136 and $350 \mathrm{MPa}$ for 25 to $75 \mathrm{wt} \%$ content of PHBV. The $\varepsilon_{\text {break }}$ was noticeably similar in these blends, 193 and $197 \%$, respectively. Interestingly, it was not noticed for $50 \mathrm{wt} \%$ of PHBV. A completely different profile was observed in the 50PLA/50PHBV/0h stress-strain curve showing the lowest $\sigma_{\text {break }}, \varepsilon_{\text {break }}$ and $E$ values, i.e., $15.2 \mathrm{MPa}, 9.8 \%$ and $311 \mathrm{MPa}$. As already mentioned in this work, PLA and PHBV are immiscible polymers. Thus, the increased PHBV content in the blend system up to $50 \mathrm{wt} \%$ must cause phase separation due to the decreased compatibility of the blend which can lead to a reduction of both the $\sigma_{\text {break }}$ and $\varepsilon_{\text {break }}$, resulting in samples with very poor mechanical properties from the unstable network formed from the immiscible polymers $[3,18]$. While the 75PLA/25PHBV/0h blend showed the sum of both the characteristic stress-strain curves of PLA and PHBV, the 25PLA/75PHBV/0h blend mainly showed the PHBV profile. In addition, because of the immiscibility of the polymers, the accelerated weathering and the individual degradation process of each polymer in the blend must explain the observed high values for the standard deviation, that were significantly higher for 50PLA/50PHBV. Judging by the heterogeneous appearance of this blend, these results were expected. High values of uncertainty was also observed by Zhao et al. [39] for the blend combination of $70 \mathrm{wt} \%$ of PLA and $30 \mathrm{wt} \%$ PHBV.

The stress-strain results show that whatever the content of each polymer in the blend, the $\varepsilon_{\text {break }}$ drops after $500 \mathrm{~h}$ of accelerated weathering. The main
Table 5. Mechanical properties of PLA/PHBV blends before and after accelerated weathering.

\begin{tabular}{|l|c|c|c|}
\hline & $\begin{array}{c}\boldsymbol{\sigma}_{\text {break }} \\
{[\mathbf{M P a}]}\end{array}$ & $\begin{array}{c}\boldsymbol{\varepsilon} \\
{[\%]}\end{array}$ & $\begin{array}{c}\boldsymbol{E} \\
{[\mathbf{M P a}]}\end{array}$ \\
\hline PLA & $25.5 \pm 1.2$ & $1.8 \pm 0.4$ & $3036 \pm 101$ \\
\hline PHBV & $34.2 \pm 1.7$ & $730 \pm 40$ & $181 \pm 6$ \\
\hline 75PLA/25PHBV/0h & $29.0 \pm 1.9$ & $197 \pm 36$ & $1136 \pm 94$ \\
\hline 75PLA/25PHBV/500h & $22.4 \pm 4.1$ & $1.8 \pm 0.2$ & $1337 \pm 11$ \\
\hline 75PLA/25PHBV/1000h & $9.9 \pm 2.5$ & $1.8 \pm 0.4$ & $619 \pm 162$ \\
\hline 75PLA/25PHBV/2000h & - & - & - \\
\hline 50PLA/50PHBV/0h & $15.2 \pm 0.6$ & $9.8 \pm 0.6$ & $311 \pm 45$ \\
\hline 50PLA/50PHBV/500h & $2.1 \pm 3.0$ & $1.1 \pm 0.7$ & $156 \pm 181$ \\
\hline 50PLA/50PHBV/1000h & - & - & - \\
\hline 50PLA/50PHBV/2000h & - & - & - \\
\hline 25PLA/75PHBV/0h & $19.0 \pm 2.9$ & $193 \pm 36$ & $350 \pm 57$ \\
\hline 25PLA/75PHBV/500h & $3.2 \pm 1.8$ & $1.1 \pm 0.3$ & $293 \pm 57$ \\
\hline 25PLA/75PHBV/1000h & $0.5 \pm 0.2$ & $0.7 \pm 0.1$ & $74.6 \pm 32.9$ \\
\hline 25PLA/75PHBV/2000h & - & - & - \\
\hline
\end{tabular}

changes occurred in the PHBV phase, showing the vulnerability of PHBV to weathering degradation. The mechanical properties of neat PHBV decreased over the weathering time, most probably due to a decrease in $M_{\mathrm{w}}[27,40]$. All the samples show that the most significant changes of mechanical properties proceeded during the first period of $500 \mathrm{~h}$ and continued up to $2000 \mathrm{~h}$. The 50PLA/50PHBV/2000h sample showed the most pronounced degradation, as was expected from the damaged surface observed in Figure 1 at the beginning of the study. The 50PLA/ 50PHBV $/ 1000 \mathrm{~h}$ samples were already significantly cracked and brittle such as observed before, for this reason they were also not tested.

In the case of the 75PLA/25PHBV blend, the mechanical properties more gradually decreased with increasing weathering time, as noted in Table 5. Qiang et al. [41] and Zhang et al. [42] explained this to be a certain extent of miscibility being attributed to a transesterification reaction occurring during melt blending preparation at low content of PHBV. The resultant copolymers compatibilize the two neat components to improve the PHBV/PLA blend miscibility achieving a more ductile network. The Young's modulus of the 75PLA/25PHBV/500h increased slightly from 1136 to $1337 \mathrm{MPa}$.

The weathering exposure and low PHBV content in the 75PLA/25PHBV blend provided toughness to the PLA matrix during the degradation and increased the crystallinity of the PLA, as was observed from the DSC analysis. This increase can be caused by a combination of at least two factors. The proposed 
explanation is based on the amorphous character of PLA and its high content in each blend. PLA chains offer less resistance to UV and water permeation, which means PLA will first suffer chain scission of its long chains followed by the re-organization of this polymer in crystalline regions. However, PHBV exhibits a semi-crystalline structure and both phases simultaneously undergo weathering degradation. This additional re-organization step of PLA degradation should be enough to delay the degradation process of the blends because some properties will be improved due to the change of the PLA structure from amorphous to semi-crystalline. In addition, the resultant crystallites exhibit a physical barrier to protect the PHBV. In the 75PLA/25PHBV blend the small fraction of PHBV promotes the nucleation effect leading to thinner crystallites formation during both the preparation and weathering of the samples $[3,5$, 43]. As a consequence of the increased crystallinity of the PLA, it was also expected that the $E$ would increase. However, it is known that crystalline morphology induces a more ductile or stiffer material, depending on whether the crystals are large or small. The blend morphology could therefore be the reason for the observed results. The degradation continued after $500 \mathrm{~h}$, with the $E, \sigma_{\text {break }}$ and $\varepsilon_{\text {break }}$ values decreasing, but the process is much less prominent. After $2000 \mathrm{~h}$, all the blends showed to be completely degraded and stress-strain measurements were not possible.

\section{Conclusions}

Investigation of the accelerated weathering effect over periods of 500, 1000 and $2000 \mathrm{~h}$ on the properties of PLA/PHBV blends showed that degradation influenced different characteristics according to the blend composition.

All the analyses showed the immiscibility of the PLA and PHBV. Some holes and cavities were clearly noted in the SEM analysis of 50PLA/50PHBV/0h, which promoted the absorption and diffusion of water through the polymer bulk, as well as the UV penetration resulting in faster polymer chain cleavage. XRD analysis showed the lower resistance of PHBV to weathering attack, and suggested a nucleating effect of the $25 \mathrm{wt} \%$ of PHBV on PLA and a later surface degradation. The visual aspect of the surfaces of the PLA/PHBV blends changed from glossy and smooth to cracked and pale yellow after $2000 \mathrm{~h}$ caused by photodegradation of the blends by a Norrish II mechanism, confirmed by the generation of a new $\mathrm{C}=\mathrm{C}$ band in FTIR analysis. An increase in polar groups (confirmed by FTIR and $C A$ ) on the polymer surface during degradation allowed an increase in the hydrophilicity for all the blends, which had a positive effect on the hydrolytic degradation. During weathering exposure, several short chains formed as a result of chain scission of the amorphous phase of PLA, leading to chain re-organization and promoting the crystallinity of the samples. DSC showed an improvement in crystallization of PLA due to UV and moisture degradation, but also the positive effect played by PHBV crystals on the nucleation of PLA. The PLA crystals acted as a barrier against weathering degradation of the PHBV matrix because DSC showed an overall increase in the crystallinity of PHBV with increasing PLA content. A significant general improvement in the mechanical properties was observed for the blends compared to the neat polymers. Clearly, PLA changed from brittle to ductile after blended with PHBV. However, the elongation at break dropped after $500 \mathrm{~h}$ of accelerated weathering whatever the blend composition, while an increase in Young's modulus was observed for 75PLA/25PHBV/500h due to the effect of the higher crystallinity of PLA formed after weathering and enhanced by the presence of PHBV acting as nucleating agent. To the contrary, the degradation was the most pronounced for $50 \mathrm{PLA} / 50 \mathrm{PHBV} / 2000 \mathrm{~h}$ as a result of segregation and immiscibility of the individual components. The main changes occurred in the corresponding PHBV phase, showing the vulnerability of PHBV to weathering degradation, although the presence of low PHBV content promoted a more gradual degradation process.

\section{Acknowledgements}

The authors would also like to thank the Qatar University Central Laboratories Unit (QUCLU) for their assistance with the SEM measurements of the samples. This research was funded through the Qatar University Collaborative Grant No. QUCG-CAM 19/20-3. The findings achieved herein are solely the responsibility of the authors.

\section{References}

[1] Haider T. P., Völker C., Kramm J., Landfester K., Wurm F. R.: Plastics of the future? The impact of biodegradable polymers on the environment and on society. Angewandte Chemie - International Edition, 58, 50-62 (2019). https://doi.org/10.1002/anie.201805766 
[2] Nair L. S., Laurencin C. T.: Biodegradable polymers as biomaterials. Progress in Polymer Science, 32, 762-798 (2007).

https://doi.org/10.1016/j.progpolymsci.2007.05.017

[3] Kanda G. S., Al-Qaradawi I., Luyt A. S.: Morphology and property changes in PLA/PHBV blends as function of blend composition. Journal of Polymer Research, 25, 196/1-196/9 (2018).

https://doi.org/10.1007/s10965-018-1586-3

[4] Liu Q., Wu C., Zhang H., Deng B.: Blends of polylactide and poly(3-hydroxybutyrate-co-3-hydroxyvalerate) with low content of hydroxyvalerate unit: Morphology, structure, and property. Journal of Applied Polymer Science, 132, 42689/1-42689/9 (2015).

https://doi.org/10.1002/app.42689

[5] Zembouai I., Kaci M., Bruzaud S., Benhamida A., Corre Y-M., Grohens Y.: A study of morphological, thermal, rheological and barrier properties of poly(3-hydroxybutyrate-co-3-hydroxyvalerate)/polylactide blends prepared by melt mixing. Polymer Testing, 32, 842-851 (2013).

https://doi.org/10.1016/j.polymertesting.2013.04.004

[6] Armentano I., Fortunati E., Burgos N., Dominici F., Luzi F., Fiori S., Jiménez A., Yoon K., Ahn J., Kang S., Kenny J. M.: Processing and characterization of plasticized PLA/PHB blends for biodegradable multiphase systems. Express Polymer Letters, 9, 583-596 (2015). https://doi.org/10.3144/expresspolymlett.2015.55

[7] Montagna L. S., do Amaral Montanheiro T. L., Borges A. C., Koga-Ito C. Y., Lemes A. P., Rezende M. C.: Influence of photodegradation with UV radiation in biotreatment with Paecilomyces variotti on PHBV/GNS nanocomposites. IET Nanobiotechnology, 12, 285-291 (2018).

https://doi.org/10.1049/iet-nbt.2017.0020

[8] Santonja-Blasco L., Ribes-Greus A., Alamo R. G.: Comparative thermal, biological and photodegradation kinetics of polylactide and effect on crystallization rates. Polymer Degradation and Stability, 98, 771-784 (2013). https://doi.org/10.1016/j.polymdegradstab.2012.12.012

[9] Bonartsev A. P., Boskhomodgiev A. P., Iordanskii A. L., Bonartseva G. A., Rebrov V., Makhina T. K., Myshkina V. L., Yakovlev S. A., Filatova E. A., Bagrov D. V, Zaikov G. E., Boskhomodgiev A. P., Iordanskii A. L., Bonartseva G. A.: Hydrolytic degradation of poly(3-hydroxybutyrate), polylactide and their derivatives: Kinetics, crystallinity, and surface morphology. Molecular Crystals and Liquid Crystals, 556, 288-300 (2012). https://doi.org/10.1080/15421406.2012.635982

[10] dos Santos Rosa D., Calil M. R., das Graças Fassina Guedes C., Rodrigues T. C.: Biodegradability of thermally aged PHB, PHB-V, and PCL in soil compostage. Journal of Polymers and the Environment, 12, 239-245 (2004).

https://doi.org/10.1007/s10924-004-8151-3
[11] Tsuji H., Echizen Y., Nishimura Y.: Enzymatic degradation of poly(L-lactic acid): Effects of UV irradiation. Journal of Polymers and the Environment, 14, 239-248 (2006).

https://doi.org/10.1007/s10924-006-0023-6

[12] Antunes A., Popelka A., Aljarod O., Hassan M. K., Luyt A. S.: Effects of rutile- $\mathrm{TiO}_{2}$ nanoparticles on accelerated weathering degradation of poly(lactic acid). Polymers, 12, 1096/1-1096/25 (2020).

https://doi.org/10.3390/polym12051096

[13] Antunes A., Popelka A., Aljarod O., Hassan M. K., Kasak P., Luyt A. S.: Accelerated weathering effects on poly(3-hydroxybutyrate-co-3-hydroxyvalerate) (PHBV) and $\mathrm{PHBV} / \mathrm{TiO}_{2}$ nanocomposites. Polymers, 12, 1743/11743/28 (2020).

https://doi.org/doi:10.3390/polym12081743

[14] Goldstein J. I., Newbury D. E., Echlin P., Joy D. C., Romig Jr. A. D., Lyman C. E., Fiori C., Lifshin E.: Coating and conductivity techniques for SEM and microanalysis. in 'Scanning electron microscopy and X-ray microanalysis' (eds.: Goldstein J. I., Newbury D. E., Echlin P., Joy D. C., Romig A. D., Lyman C. E., Fiori C., Lifshin E.) Springer, Boston, 671-740 (1992). https://doi.org/10.1007/978-1-4613-0491-3 13

[15] Ostafinska A., Fortelny I., Nevoralova M., Hodan J., Kredatusova J., Slouf M.: Synergistic effects in mechanical properties of PLA/PCL blends with optimized composition, processing, and morphology. RSC Advances, 5, 98971-98982 (2015).

https://doi.org/10.1039/c5ra21178f

[16] Scandola M., Ceccorulli G., Pizzoli M., Gazzano M.: Study of the crystal phase and crystallization rate of bacterial poly(3-hydroxybutyrate-co-3-hydroxyvalerate). Macromolecules, 25, 1405-1410 (1992). https://doi.org/10.1021/ma00031a008

[17] Abdelwahab M. A., Flynn A., Chiou B-S., Imam S., Orts W., Chiellini E.: Thermal, mechanical and morphological characterization of plasticized PLA-PHB blends. Polymer Degradation and Stability, 97, 1822-1828 (2012).

https://doi.org/10.1016/j.polymdegradstab.2012.05.036

[18] Gasmi S., Hassan M. K., Luyt A. S.: Crystallization and dielectric behavior of PLA and PHBV in PLA/PHBV blends and PLA/PHBV/TiO 2 nanocomposites. Express Polymer Letters, 13, 199-212 (2019).

https://doi.org/10.3144/expresspolymlett.2019.16

[19] Lamour G., Yip C. K., Li H., Gsponer J.: High intrinsic mechanical flexibility of mouse prion nanofibrils revealed by measurements of axial and radial Young's moduli. ACS Nano, 8, 3851-3861 (2014).

https://doi.org/10.1021/nn5007013

[20] Hakkarainen M.: Aliphatic polyesters: Abiotic and biotic degradation and degradation products. in 'Degradable aliphatic polyesters' (ed.: Albertsson A-C.) Springer, Berlin, Vol 157, 113-138 (2002). https://doi.org/10.1007/3-540-45734-8 4 
[21] Sato H., Ando Y., Mitomo H., Ozaki Y.: Infrared spectroscopy and X-ray diffraction studies of thermal behavior and lamella structures of poly(3-hydroxybutyrate-co-3-hydroxyvalerate) (P(HB-co-HV)) with PHBtype crystal structure and PHV-type crystal structure. Macromolecules, 44, 2829-2837 (2011).

https://doi.org/10.1021/ma102723n

[22] Puchalski M., Kwolek S., Szparaga G., Chrzanowski M., Krucinska I.: Investigation of the influence of PLA molecular structure on the crystalline forms ( $\alpha^{\prime}$ and $\alpha$ ) and mechanical properties of wet spinning fibres. Polymers, 9, 18/1-18/13 (2017).

https://doi.org/10.3390/polym9010018

[23] Wiggins J. S., Hassan M. K., Mauritz K. A., Storey R. F.: Hydrolytic degradation of poly(D,L-lactide) as a function of end group: Carboxylic acid vs. hydroxyl. Polymer, 47, 1960-1969 (2006).

https://doi.org/10.1016/j.polymer.2006.01.021

[24] Arrieta M. P., Samper M. D., Aldas M., López J.: On the use of PLA-PHB blends for sustainable food packaging applications. Materials, 10, 1008/1-1008/26 (2017). https://doi.org/10.3390/ma10091008

[25] Townsend K. J., Busse K., Kressler J., Scholz C.: Contact angle, WAXS, and SAXS analysis of poly( $\beta$-hydroxybutyrate) and poly(ethylene glycol) block copolymers obtained via Azotobacter vinelandii UWD. Biotechnology Progress, 21, 959-964 (2005).

https://doi.org/10.1021/bp050044h

[26] Chávez-Montes W. M., González-Sánchez G., LópezMartínez E. I., De Lira-Gómez P., Ballinas-Casarrubias L., Flores-Gallardo S.: Effect of artificial weathering on PLA/nanocomposite molecular weight distribution. Polymers, 7, 760-776 (2015).

https://doi.org/10.3390/polym7040760

[27] Wei L., McDonald A. G.: Accelerated weathering studies on the bioplastic, poly(3-hydroxybutyrate-co-3-hydroxyvalerate). Polymer Degradation and Stability, 126, 93-100 (2016).

https://doi.org/10.1016/j.polymdegradstab.2016.01.023

[28] Schusser S., Menzel S., Bäcker M., Leinhos M., Poghossian A., Wagner P., Schöning M. J.: Degradation of thin poly(lactic acid) films: Characterization by capacitance-voltage, atomic force microscopy, scanning electron microscopy and contact-angle measurements. Electrochimica Acta, 113, 779-784 (2013). https://doi.org/10.1016/j.electacta.2013.08.025

[29] Meaurio E., López-Rodríguez N., Sarasua J. R.: Infrared spectrum of poly(L-lactide): Application to crystallinity studies. Macromolecules, 39, 9291-9301 (2006). https://doi.org/10.1021/ma061890r

[30] Pluta M.: Melt compounding of polylactide/organoclay: Structure and properties of nanocomposites. Journal of Polymer Science Part B: Polymer Physics, 44, 33923405 (2006).

https://doi.org/10.1002/polb.20957
[31] Rydz J., Wolna-Stypka K., Musioł M., Szeluga U., Janeczek H., Kowalczuk M.: Further evidence of polylactide degradation in paraffin and in selected protic media. A thermal analysis of eroded polylactide films. Polymer Degradation and Stability, 98, 1450-1457 (2013).

https://doi.org/10.1016/j.polymdegradstab.2013.05.005

[32] Lv S., Liu X., Gu J., Jiang Y., Tan H., Zhang Y.: Effect of glycerol introduced into PLA based composites on the UV weathering behavior. Construction and Building Materials, 144, 525-531 (2017).

https://doi.org/10.1016/j.conbuildmat.2017.03.209

[33] Gorrasi G., Milone C., Piperopoulos E., Lanza M., Sorrentino A.: Hybrid clay mineral-carbon nanotube-PLA nanocomposite films. Preparation and photodegradation effect on their mechanical, thermal and electrical properties. Applied Clay Science, 71, 49-54 (2013). https://doi.org/10.1016/j.clay.2012.11.004

[34] Mosnáčková K., Danko M., Šišková A., Falco L. M., Janigová I., Chmela Š., Vanovčanová Z., Omaníková L., Chodák I., Mosnáček J.: Complex study of the physical properties of a poly(lactic acid)/poly(3-hydroxybutyrate) blend and its carbon black composite during various outdoor and laboratory ageing conditions. RSC Advances, 7, 47132-47142 (2017).

https://doi.org/10.1039/c7ra08869h

[35] Mokhena T. C., Sefadi J. S., Sadiku E. R., John M. J., Mochane M. J., Mtibe A.: Thermoplastic processing of PLA/cellulose nanomaterials composites. Polymers, 10, 1363/1-1363/29 (2018).

https://doi.org/10.3390/polym10121363

[36] Zhuang W., Liu J., Zhang J. H., Hu B. X., Shen J.: Preparation, characterization, and properties of $\mathrm{TiO}_{2} /$ PLA nanocomposites by in situ polymerization. Polymer Composites, 30, 1075-1080 (2008).

https://doi.org/10.1002/pc.20658

[37] Ausejo J. G., Rydz J., Musioł M., Sikorska W., Sobota M., Włodarczyk J., Adamus G., Janeczek H., Kwiecień I., Hercog A., Johnston B., Khan H. R., Kannappan V., Jones K. R., Morris M. R., Jiang G., Radecka I., Kowalczuk M.: A comparative study of three-dimensional printing directions: The degradation and toxicological profile of a PLA/PHA blend. Polymer Degradation and Stability, 152, 191-207 (2018). https://doi.org/10.1016/j.polymdegradstab.2018.04.024

[38] Mittal V.: Functional polymer blends: Synthesis, properties, and performance. CRC Press, New York (2012).

[39] Zhao H., Cui Z., Wang X., Turng L-S., Peng X.: Processing and characterization of solid and microcellular poly(lactic acid)/polyhydroxybutyrate-valerate (PLA/ PHBV) blends and PLA/PHBV/clay nanocomposites. Composites Part B: Engineering, 51, 79-91 (2013). https://doi.org/10.1016/j.compositesb.2013.02.034 
[40] Kuciel S., Mazur K., Jakubowska P.: Novel biorenewable composites based on poly(3-hydroxybutyrate-co3-hydroxyvalerate) with natural fillers. Journal of Polymers and the Environment, 27, 803-815 (2019). https://doi.org/10.1007/s10924-019-01392-4

[41] Qiang T., Wang J., Wolcott M. P.: Facile fabrication of $100 \%$ bio-based and degradable ternary cellulose/ PHBV/PLA composites. Materials, 11, 330/1-330/14 (2018).

https://doi.org/10.3390/ma11020330
[42] Zhang L., Xiong C., Deng X.: Miscibility, crystallization and morphology of poly( $\beta$-hydroxybutyrate)/poly (D,L-lactide) blends. Polymer, 37, 235-241 (1996). https://doi.org/10.1016/0032-3861(96)81093-7

[43] Tsuji H., Echizen Y., Nishimura Y.: Photodegradation of biodegradable polyesters: A comprehensive study on poly(L-lactide) and poly( $\varepsilon$-caprolactone). Polymer Degradation and Stability, 91, 1128-1137 (2006). https://doi.org/10.1016/j.polymdegradstab.2005.07.007 